\title{
EXHIBITION REVIEWS
}

\section{Museum of Russian Icons, Clinton, Massachusetts}

After major disasters, it is common for communities to gather at places of worship to give thanks for what was salvaged, pray for what was lost, and draw comfort, strength, and hope from shared experiences. But the global COVID-19 pandemic is a different and more insidious disaster. Farther reaching than bombs, fires, or collapsed buildings, the contagion eroded community and family ties, and contaminated houses of refuge, among them museums. Many museums closed, others laid off key personnel, some closed altogether-smaller tragedies among the collective global toll.

With vaccinations becoming more widely available, and public attractions beginning to resume operations, museums, too, have been cautiously re-opening. The museum community should eagerly await the inevitable studies of how attendance has changed, but in the meantime, it is perhaps equally intriguing to consider which museum lures us first. For this museum professional it was the Museum of Russian Icons in a small town about an hour northwest of Boston. When I moved to the area five years ago, I heard about it. It is the largest collection outside of Russia, but I had not yet visited, despite the fact that I am a Medievalist and Iconologist by training. I took for granted that I knew what to expect. In fairness, icons possess a rather famous similarity. But as the pandemic restrictions loosened, I found myself drawn inexorably toward them.

The Museum of Russian Icons is small, situated at the edge of a tiny community park that seemed to contain all local options for religious worship. Indeed, the museum seemed to be a former parsonage for the neighboring Episcopal church, though it is actually composed of an old mill, courthouse, and holding cells with contemporary additions. This is not visually evident and finding myself there on Sunday before noon, with church bells tolling, the setting for a religious experience was in place.

This was enhanced on entry. The somber chords of a monastic choir enveloped me as I entered a dark, charcoal interior, where the first golden icons gleamed from nearby walls. The music continued and surrounded me seamlessly as I moved from one gallery to the next. Had there been incense, my senses might have believed I had wandered into a church. There is a sleek, central staircase that rises from the small basement with two galleries to a second floor with another two galleries. Ambient lighting at the base and top of the walls creates an almost stained-glass effect as it slowly cycles through a series of soft colors. The deep grey walls continued throughout, except for a small temporary exhibition space, creating a dramatic background for the glowing gilt icon surfaces.

There is nothing that might be described as innovative about the layout or interpretation in this museum. But that is not a critique, because the subject matter staunchly does not require 
it and may in fact resist trendy approaches to interpretation. Rather the museum leans into the excellence of how and what it exhibits. Outside of a handful of longer didactic panels explaining histories or concepts, the labeling is minimal. Set just outside of the visual immediacy of the icons and sharing the color of the walls, the identification labels must be sought out. This is an excellent choice. The nature of icons as "written" not by the hand of man, and drawn from previous iterations and technique, limits what can be included in traditional wall labels. Yet, the visitor comes away with a focused appreciation for the art form and the collection. The basement gallery excellently introduces the visitor to the material, technical, and symbolic components of an icon. The upper galleries describe lesser-known terms to visitors like oklad, a protective, bejeweled metal cover for icons, and iconostasis, the enormous, icon-covered screens that separate the sanctuary from the nave in many Russian Orthodox churches, and their accompanying Russian traditions. The upstairs galleries are punctuated by partial walls attached to floor and ceiling with small cables that recede into the grey, making these intrusions into the limited space minimal and welcome. The visual groupings excel at telling stories about their histories or about their style type, encouraging even the most unobservant visitor to consider the vast similarities and important distinctions. In this small space there are challenging juxtapositions like miniatures on one end and a large Maiestas Domini on the other. Yet the groupings draw the eye and create a natural, contemplative flow for visitors.

This is an exceptional art form, an exceptional collection, and an exceptional display. I daresay transcendent. I felt transported away from the struggles of last year as the glowing images and quiet music soothed my senses, as I gathered with others seeking balm and solace. In the past decades there has been an active debate about whether museums are forums or temples, the former word implying an open, welcoming, discursive space for community growth, the latter carrying elitist connotations of sacred hierarchies and outmoded practices. In the museum community's eagerness to embrace the new and seem progressive and open, it can be easy to reject what came before without appreciating what it offered. After my visit to the Museum of Russian Icons, I am newly disposed to give more careful consideration to museum-as-temple. Like the houses of worship we neglect when times are good, this museum-as-temple made me grateful for what museums have been, even as we collectively hope and strive for renewal.

Sheila K. Hoffman,

Boston, Massachusetts

\title{
Local Cultures Assisting Revitalization: 10 Years Since the Great East Japan Earthquake
}

\author{
National Museum of Ethology (Minpaku), Osaka, 3 March 2021-18 May 2021
}

Ten years have passed since the Great East Japan Earthquake that took thousands of lives and destroyed neighborhoods along the coastline. As an island nation, Japan's history has always been marked by natural disasters, and despite the destructive and merciless nature of these disasters, people have continued to rebuild communities in the same places. On the other hand, it is precisely because we have endured and survived disasters that the wisdom to recover from them has evolved over the years, especially within local cultures. 


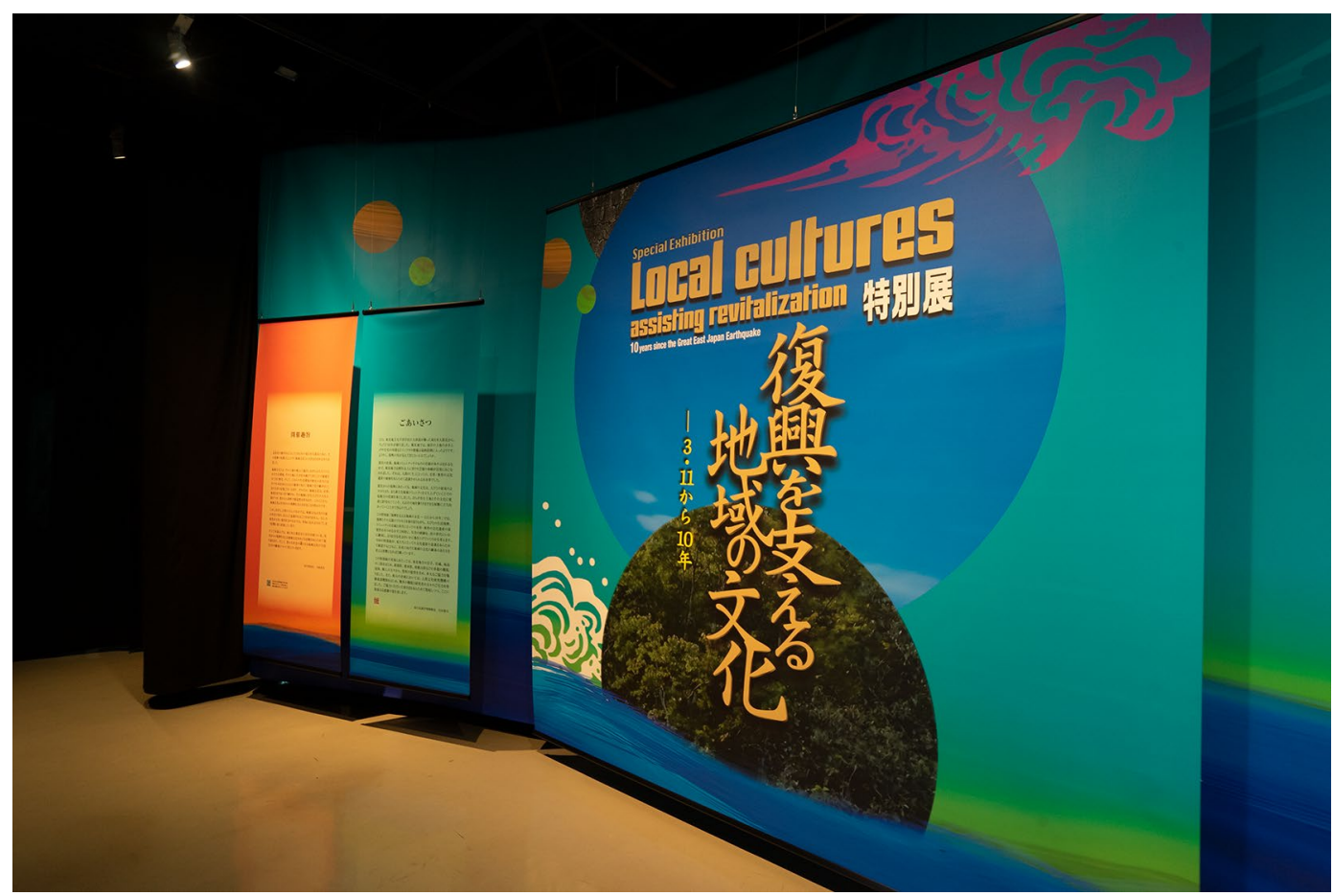

Figure 1. Entrance to the special exhibition, Local Cultures Assisting Revitalization, Minpaku, Osaka.

The special exhibition at the National Museum of Ethnology, Osaka (hereafter "Minpaku"), Local Cultures Assisting Revitalization: 10 years since the Great East Japan Earthquake, was held from 3 March to 18 May 2021, in this decennial year of the disaster (see Figure 1). As the title suggests, the exhibition shed light on the process of revitalization, and in particular highlighted the role that local cultures have played in that process. It can also be seen as the culmination of Minpaku's own research and rescue efforts conducted in close contact with local communities, the museum's expertise being combined with local resources to accelerate recovery. Discussions around natural disasters tend to focus on preparedness ahead of time, but this valuable exhibition provided insight into how museums and local cultures can act following the inevitability of catastrophes.

The introduction to the exhibition was a dimly lit room hung with black and white videos of gigantic rocks_- "Tsunami Boulder” by artist Motoyuki Shitamichi (see Figure 2)—depicting rocks that were washed ashore on Ishigaki Island, Okinawa during tsunamis over three hundred years ago. This introductory section conveyed the power of natural disasters beyond human comprehension through seemingly tranquil videos.

In the first section following the prologue, the atmosphere changed drastically with mannequins dressed in colorful costumes displayed alongside videos of local dances and rituals accompanied with the lively sounds of bells and singing. Thousands of local performing arts manifestations exist in Japan, and Tohoku is one of the regions where they are the most active. Even in the smallest villages, locals have their own festivals and dances passed down for generations. Despite the lighthearted atmosphere, all the traditional performing arts on display here were affected directly by the Great East Japan Earthquake. Performing arts are not something 


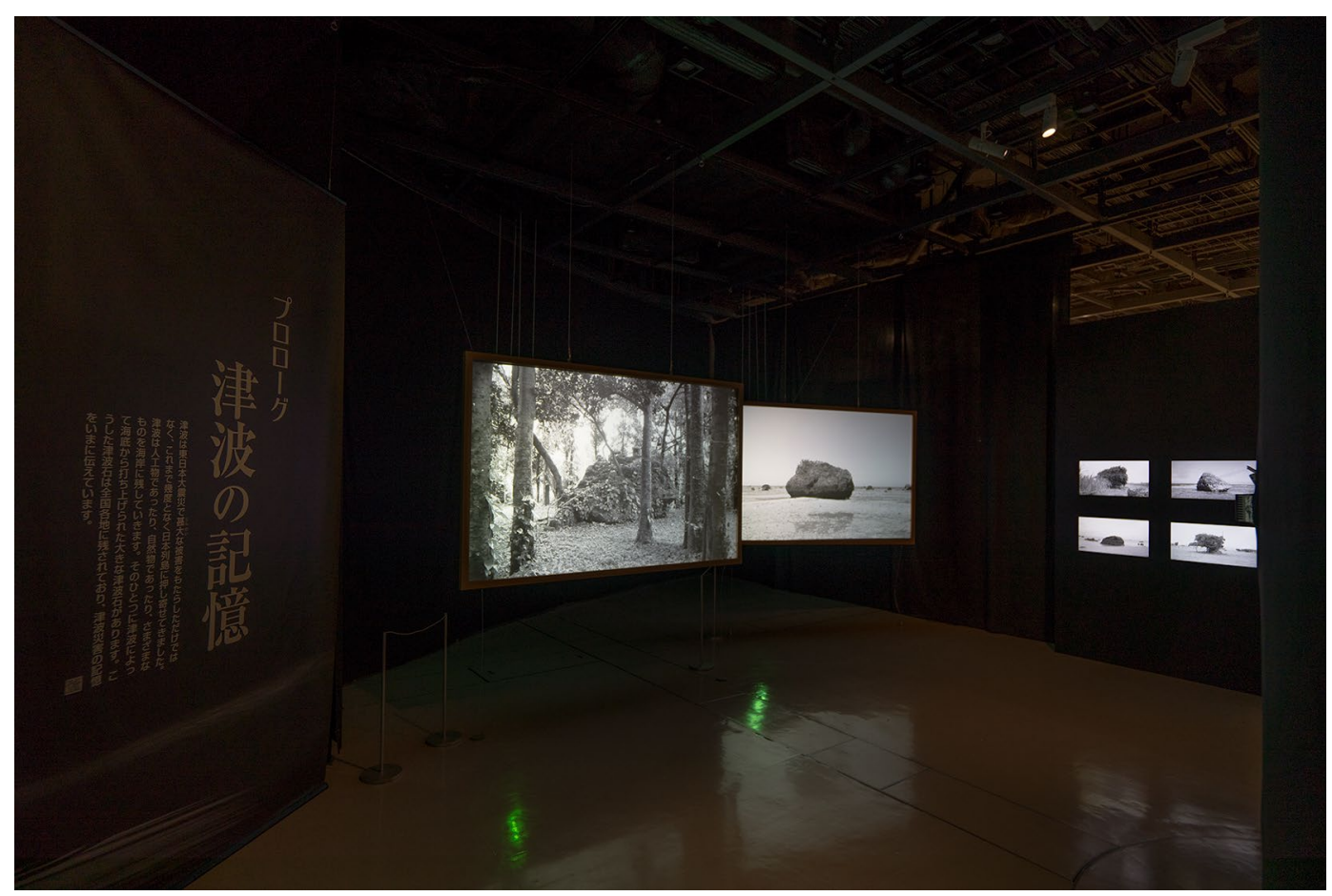

Figure 2. Introduction of the exhibition featuring "Tsunami Boulder."

that one would think of as being affected by a natural disaster. However, the fact that numerous festive instruments, costumes, and ritual objects were washed away by the tsunami, and that trained dancers and the priests who led the activities were also lost, rendered impossible the proper performance of the rituals.

One example introduced here was the Shishi-odori, or deer dance, a unique style of dance performed in Iwate (see Figure 3). Dancers wear masks with real deer horns attached with two long bamboo straps on their back, but this equipment was swept away and destroyed. However, with the support of hunters and meat processors across Japan, the Gyozan style Sasazaki Shishi-odori group was able to restore the masks and restart their performance a year after the disaster. Such speedy revival of festivals has given vitality to the affected areas, also leading to the reactivation of tourism and other forms of support for the recovery. Although the focus of revitalization tends to lean toward the rebuilding of infrastructure, culture also plays an important role in local communities. The exhibition implies that the loss of tangible assets does not equal the loss of culture itself, showing the significance of "intangible culture."

The next section contained a series of panels depicting step by step how to rescue, restore, and preserve objects damaged or submerged by the earthquake and tsunami. Featuring revitalization from a different, more technical aspect of the rescue of cultural assets and their rehabilitation, actual tools used and artifacts recovered from the mud were exhibited. Professor Shingo Hidaka of Minpaku, who organized this exhibition, also took part in the cultural property rescue in local museums during the Great East Japan Earthquake. His experiences from the Great Hanshin-Awaji Earthquake that struck the west side of Japan in 1995 became the basis of the rescue process. During disasters, collections within museums receive attention as the main target of rescue, but there is often cultural property that is recognized only by the locals and that is not stored in museums. This exhibition also focused on such examples, documenting how experts 


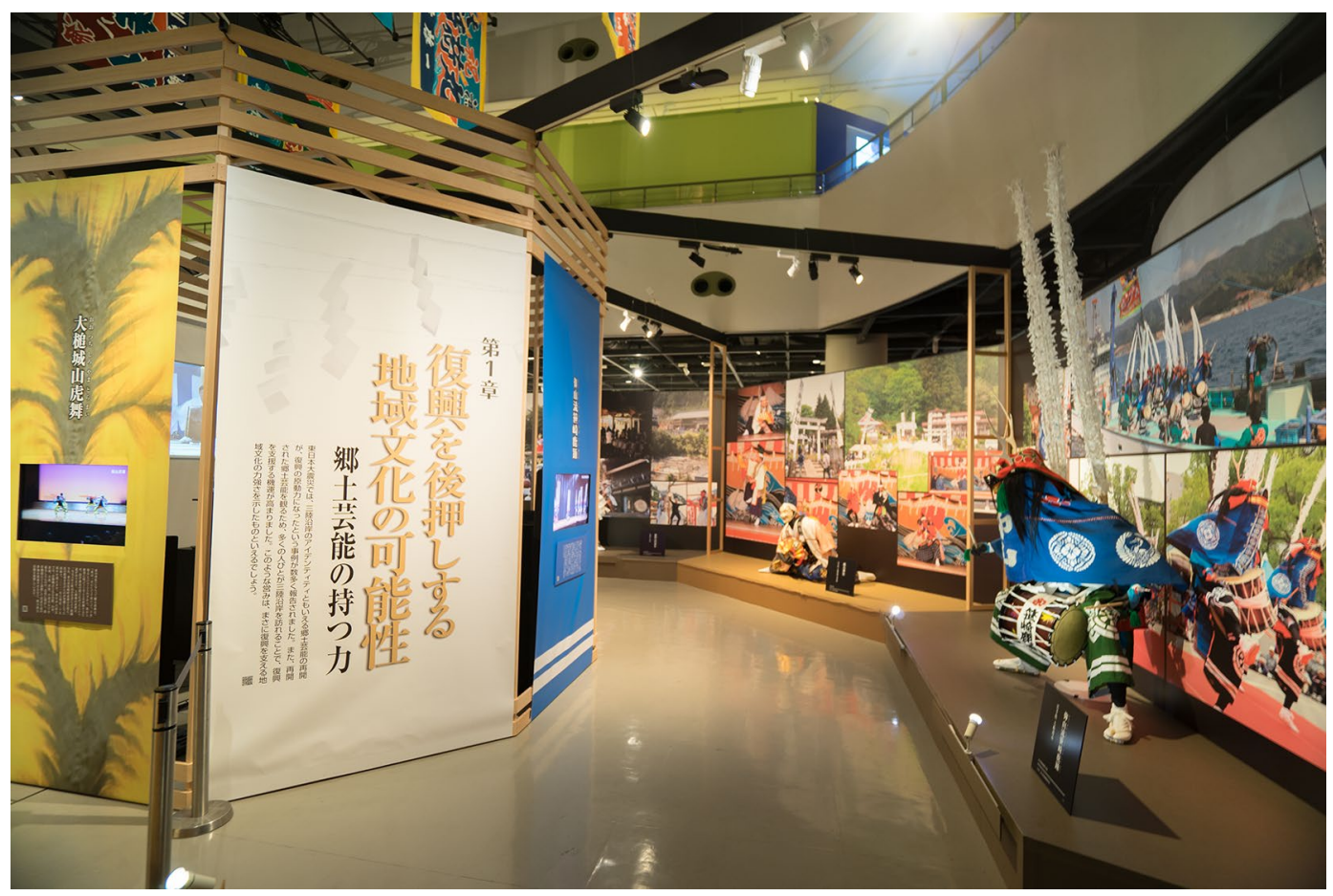

Figure 3. Exhibits of local performing arts, with the Shishi-odori costume on the right.

went into the affected communities to share their expertise, so the local people themselves could participate in the rescue and restoration process.

Visitors were guided to the second floor for the third section of the exhibition, which moved on to the process of reconstruction. Despite the effort of professionals and locals to rescue assets, communities were forced to reconsider their livelihood. At the same time, this gave an opportunity to look back on the past and to rediscover their own culture and traditions. The first half of the section focused on Oshika Peninsula, Miyagi. After the 2011 earthquake, university students conducted "reconstruction curation," interviewing the elders in the region and relating the cultural properties to personal memories to help reconstruct the past. This process helped with the accurate recognition of these cultural properties and enabled them to be passed down to the next generations. Colorful picture books and handmade cards by these students were on display, explaining the history of the region (which was collected through fieldwork) in a very approachable format.

The latter half showed another possibility for local revitalization. Tokamachi, Niigata experienced significant damage during the Chuetsu Earthquake in 2004, where local volunteers and administration carried out cultural property rescue activities. Following the rescue, the volunteer group continued to survey and archive historical documents, which revealed new facts regarding the town's textile history. A big ragged piece of paper with writing on it exhibited at the entrance was one of their discoveries (see Figure 4). Used as wrapping paper, it was made by piecing together many old documents, in which they found evidence that local textiles were presented to the Shogunate in the Edo period. Researchers at Minpaku supported optical surveys to visualize unreadable characters in this newfound document by utilizing various light sources and photographic methods. Kimonos and design patterns were also displayed, as well as all the archival activities led by local volunteers. 


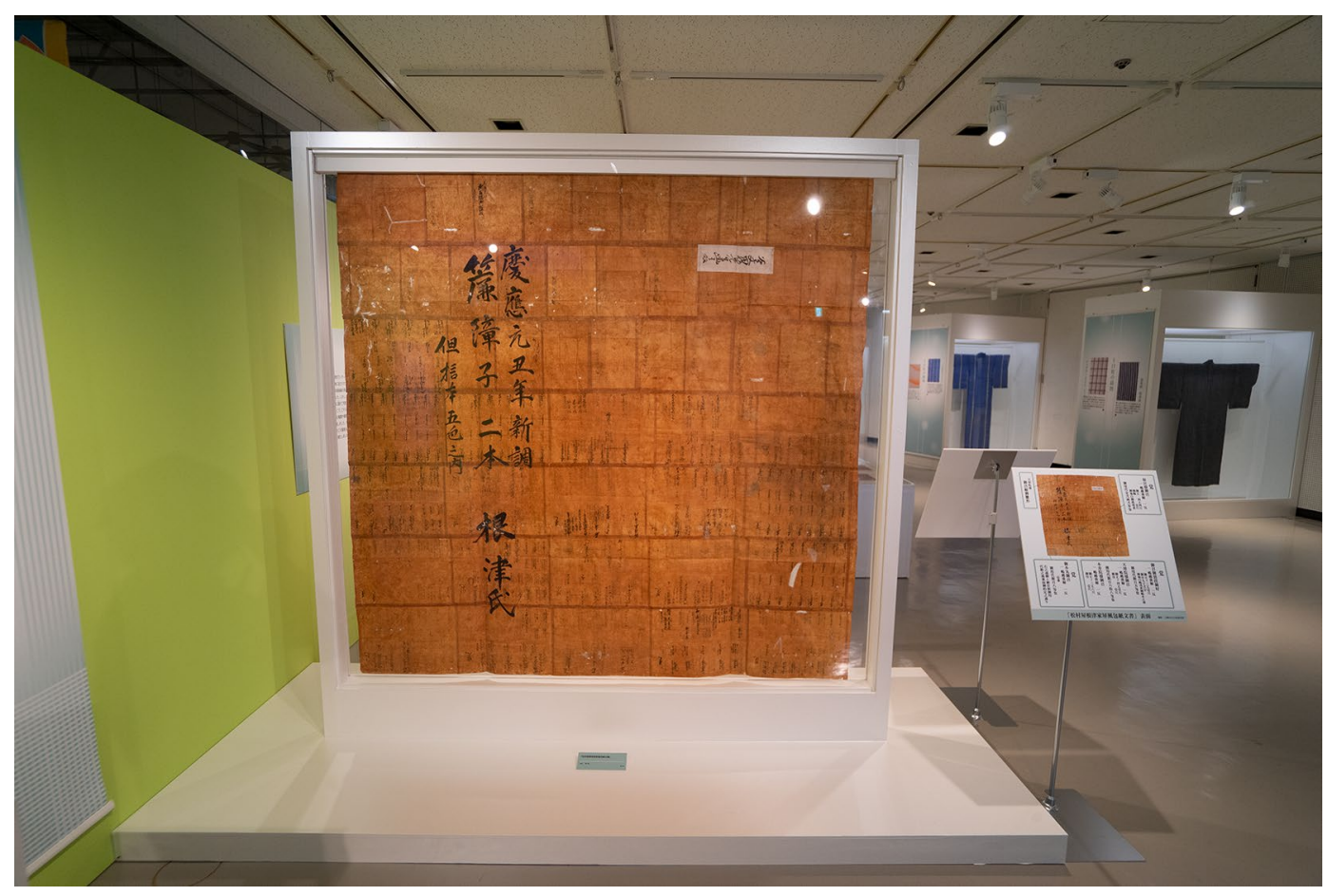

Figure 4. Wrapping paper discovered after the Chuetsu Earthquake in 2004.

The final section was titled "Preparing for Disasters." Important lessons are often passed down from our ancestors, and numerous monuments addressing past disasters can be found throughout Japan, indicating tsunami arrival points and the number of victims. Minpaku introduced "Cultural Heritage Sites Possessing Memories of Tsunamis: Database of Temples/ Shrines and Stone Monuments," a database that contains maps and information on such monuments across Japan, with the hope of helping people to engage with the past and prepare for disasters in the future. The general public can register and contribute to this database via the Internet. Following the explanation of the database, actual monuments were introduced, including those from the Edo period and a fairly new monument set up by middle school students following the 2011 tsunami.

The exhibition concluded with the theme of the inheritance of local cultures. Research results by national institutes, such as digital archives, non-contact displays to guard against COVID-19, displays for the disabled, and travel kits that can be loaned to schools were exhibited. Ten years have already passed since the earthquake, and many elementary school children born after the disaster have no memory of the event. Hopefully, these newly developed tools will continue to convey the exhibition's message to future generations long after the exhibition has closed.

Aya Tanaka,

Tokyo 


\section{Tianjin Museum of Finance, Tianjin, China}

Tianjin Museum of Finance is located on the North Jiefang Road in the city center of China's Tianjin Municipality. More than a hundred years ago, this was a concession area and the road was a "financial street" where banks from all over the world gathered, making it one of the birthplaces for Tianjin's, and even China's, modern economic and financial development. Now it is a historic heritage tourist area. In 2008, the mayor of Tianjin at the time visited the United States and saw the Museum of American Finance on Wall Street in New York. When he returned, he proposed the establishment of a local museum of Chinese finance. This museum was opened to the public in 2010 and renamed the Tianjin Museum of Finance in 2017.

This museum building was built in 1931 as the French Club, a place of social entertainment for the French expatriates in the Tianjin Concession area and the seat of the French Chamber of Commerce (see Figure 1). The building is of brick and concrete construction, with a first floor and a semi-basement. The interior of the first floor is an octagonal hall with a stained-glass window in the center of the roof, a French building in a minimalist style. After it was converted into the Museum of Finance, a statue of a bronze bull was erected at the main entrance, following the style of the one at Wall Street. This statue is distinguished by the carving of the horns and hooves of the bull in the shape of Chinese ancient coins.

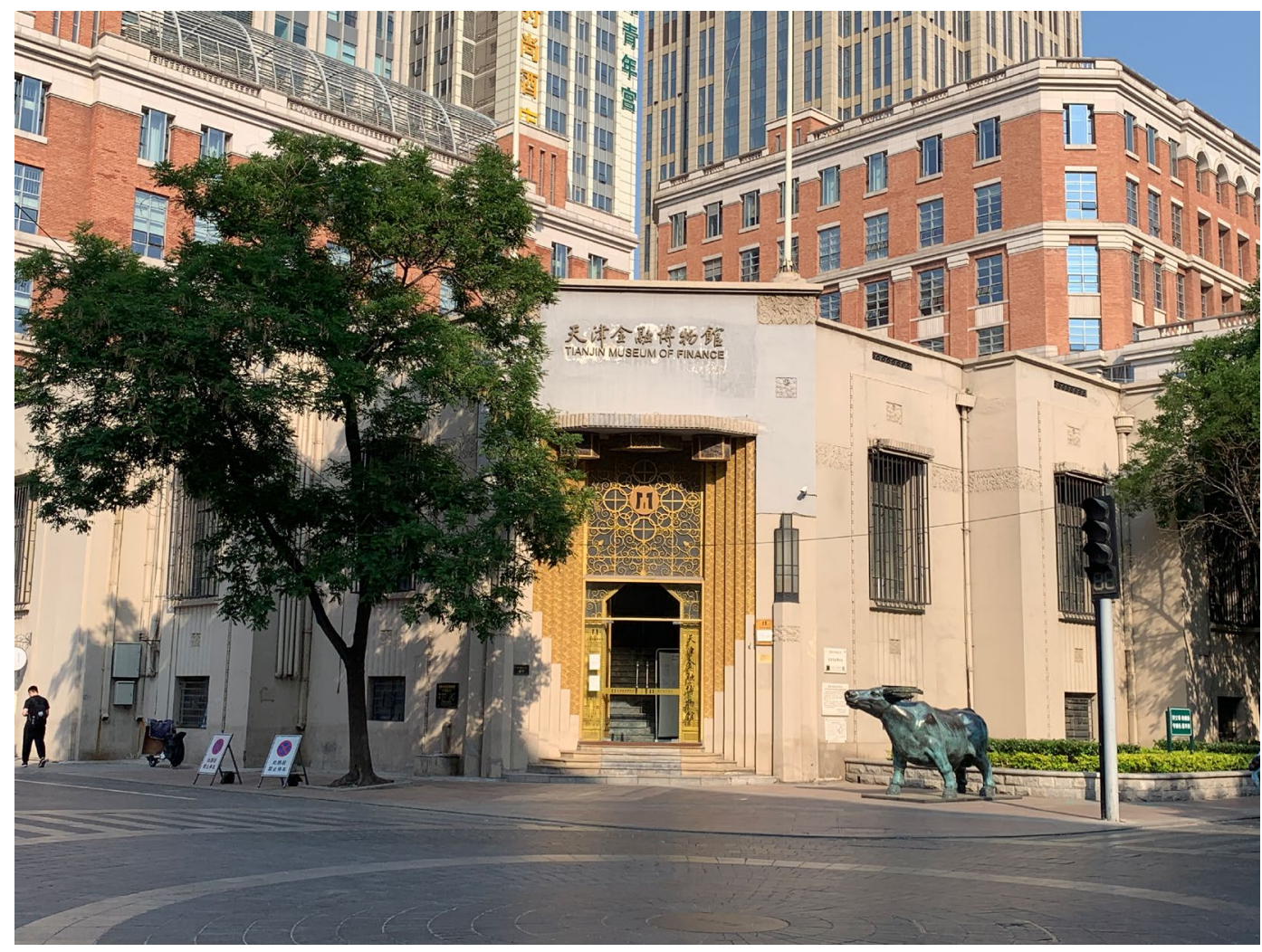

Figure 1. Tianjin Museum of Finance, Tianjin. Photo by the author. 
The exhibits on the first floor of the museum do not make the best use of the building's unique octagonal design, as the various exhibits appear cluttered. The overall exhibition layout is in a characteristic Chinese style: wherever there is space available, it is filled with as many contents as possible, even if there is no logical relationship among them. When visitors enter the first room, they may see a variety of exhibits, including ancient coins, modern banknotes, introductions to famous banks from various countries, foreign bonds from a century ago, and even models of local traditional account rooms and pawnshops in Tianjin. The second room suddenly turns into a display with panels introducing various financial scams, such as Ponzi schemes and the tulip bubble. The third room tries to convey the idea that finance is closely related to other subjects-finance and politics, finance and war, finance and technology, etc.-but it's really just a list of historical figures and introductions, which is baffling. However, it's still interesting to see portraits of Adam Smith and Alexander Hamilton in such a place. The fourth room even recreates the household furnishings of a typical Chinese family in the 1980s, which has nothing to do with the theme of finance. But those who see the museum as a tourist attraction may find it retro and interesting.

The museum attempts to use multimedia to enhance the exhibitions, but those large electronic screens and tablets, like the other exhibits, have no logical relationship to each other in terms of content, and cannot engage visitors. The large TV screens have to play a loop of fraud prevention videos in a desperate effort to get closer to the theme of "finance."

Nevertheless, there are two interactive exhibits that are interesting and the most popular for visitors. They are two transparent plastic boxes containing one million RMB and twenty one gold bricks, with handles that allow visitors to feel the actual weight of the two items (see Figure 2). These are the most participatory exhibits in the museum. Every visitor tries to handle them, which has made the metal of the handles shiny with use.
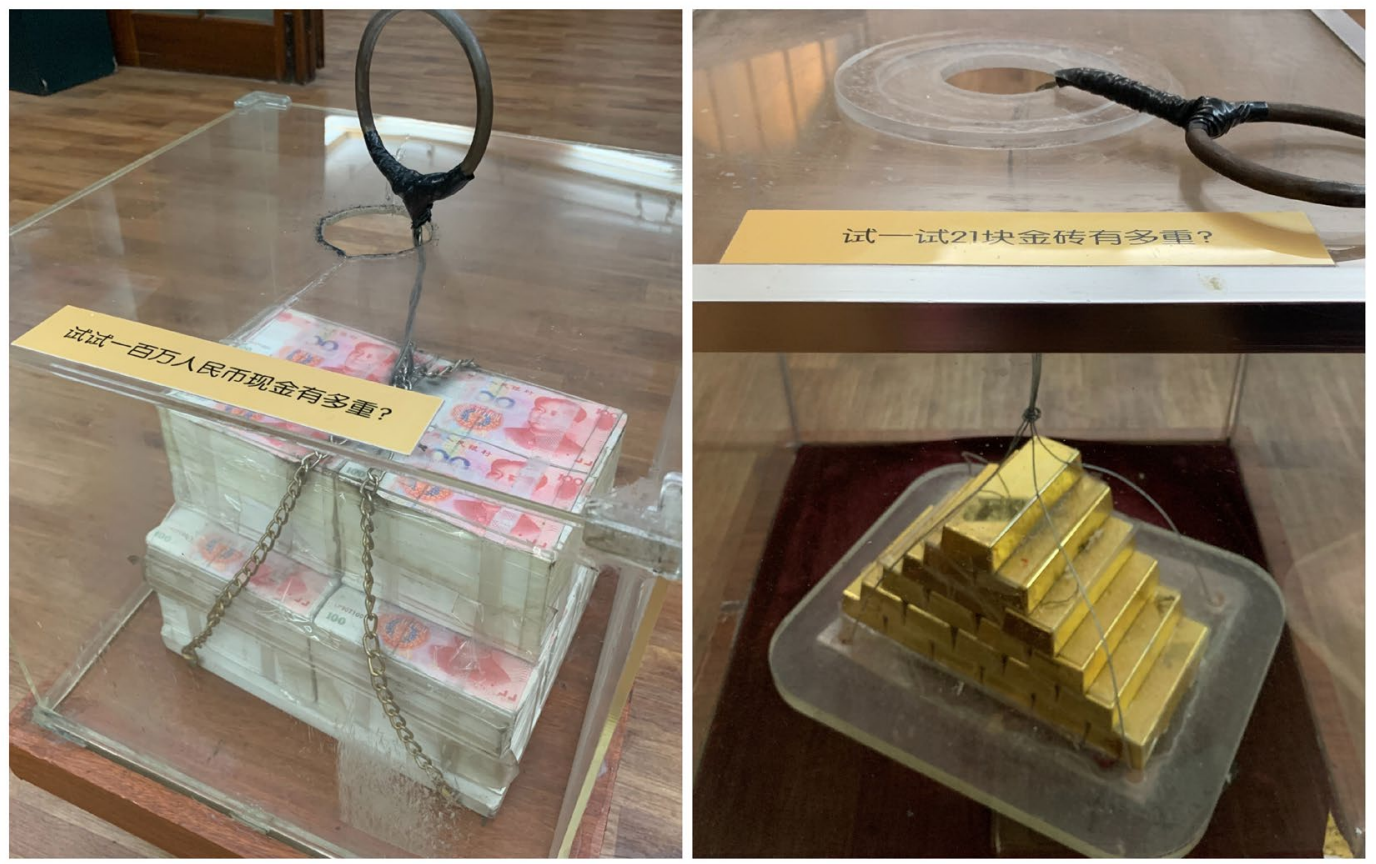

Figure 2. "Experience how much a million RMB in cash weighs" and "Experience how much 21 gold bricks weigh". Photo by the author. 
The last room, which was originally the ballroom of the French Club a hundred years ago, has been turned into a meeting room full of political propaganda that is used for daily events and lectures. The stairwell linking the two floors has an aesthetically pleasing design (see Figure 3 ). Beautiful currencies from all over the world, including the Icelandic Krona, New Zealand dollar, Cook Islands dollar, Singapore dollar, and Hong Kong dollar, are hung inside plastic bubbles. Spaces within the staircase steps, inlaid with hard glass, are used to display samples of coins from different eras in chronological order.

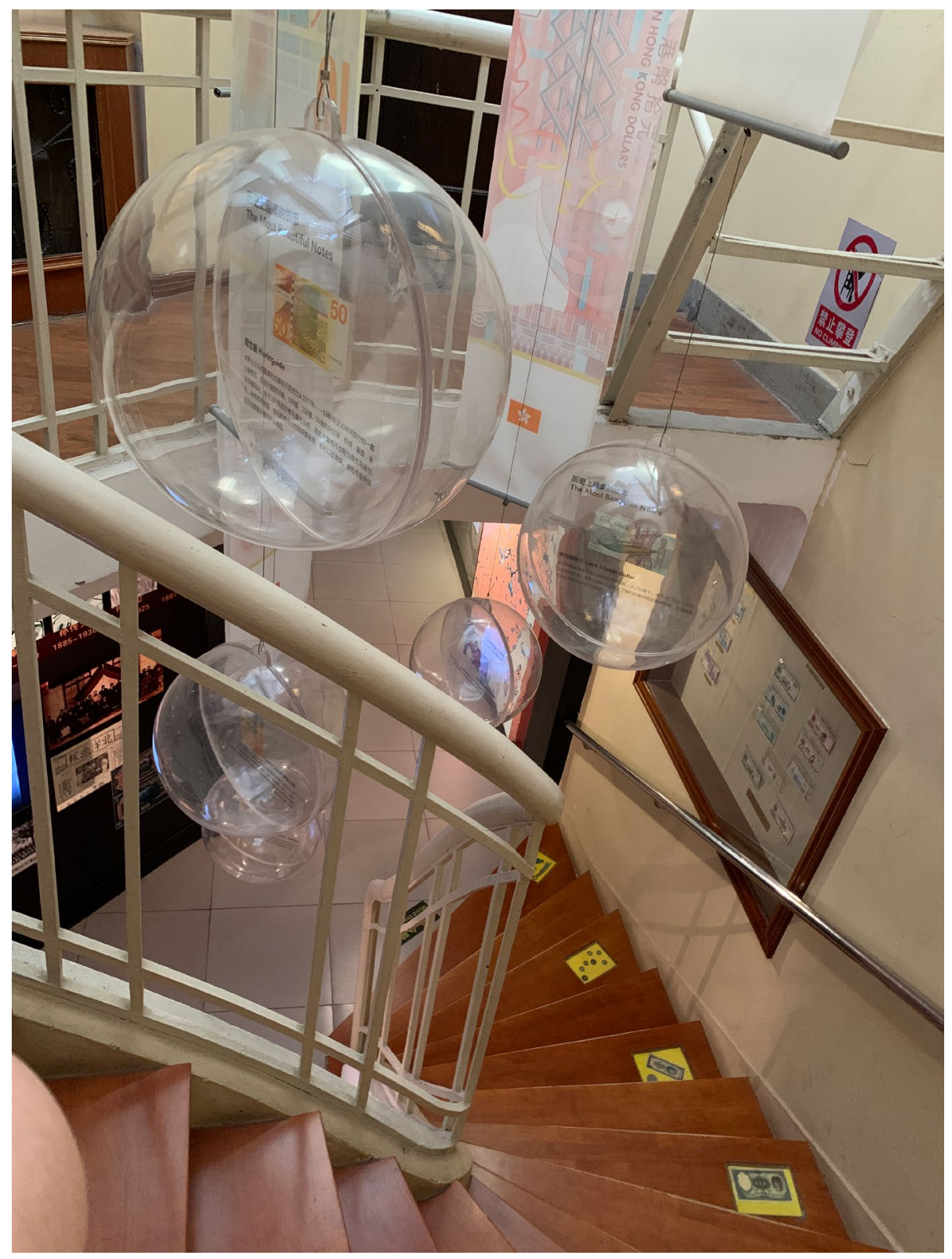

Figure 3. Stairwell leading to semi-basement. Photo by the author. 


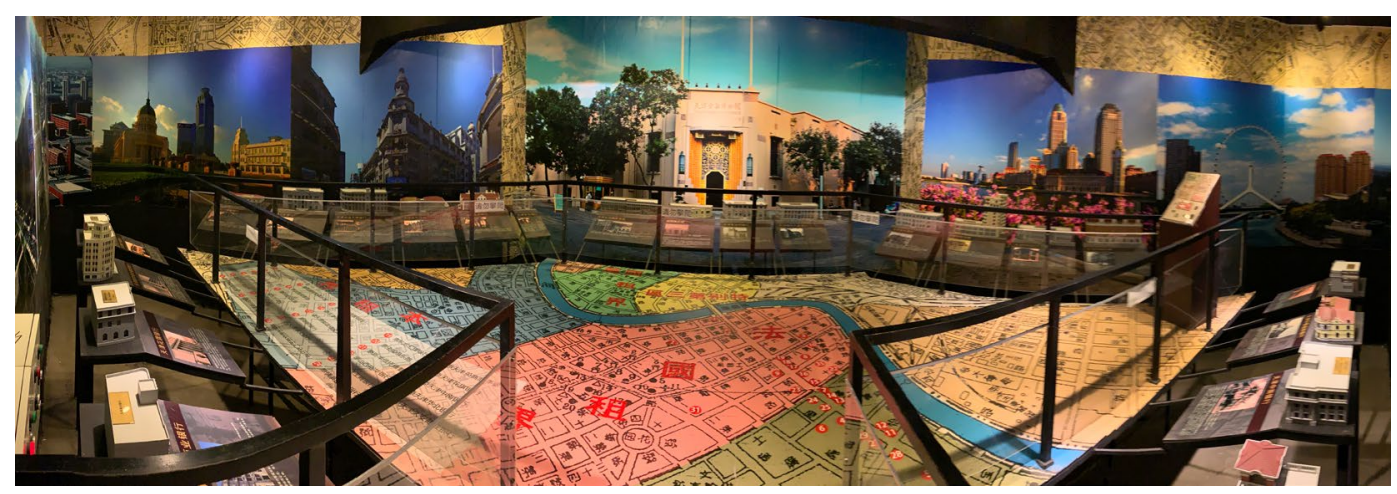

Figure 4. The exhibition room with miniature models of buildings. Photo by the author.

The semi-basement is much more spacious and cooler. Several smaller rooms are used as galleries for solo exhibitions of historical celebrities who played an influential role in the founding and development of finance in Tianjin, which include Li Hongzhang, Yuan Shikai, Liang Qichao, Sun Yat-sen, and American President Herbert Hoover. The appearance of the last name was a surprise. Visitors who read the panels carefully can see that Hoover came to China in 1898 to take over a coal mine. He lived in Tianjin in 1900 and survived the Boxer Rebellion. This is a surprising but impressive piece of historical trivia.

Deeper into the semi-basement floor, there is a relatively elaborate exhibition room, which contains miniature models and descriptions of the historical buildings along the length of "Financial Street" (see Figure 4). North Jiefang Road, where this museum is located, was the stronghold of dozens of banks more than one hundred years ago, and was the first area in China to establish a banking and finance industry. These banks included the HSBC and Standard Chartered Banks of the UK, Citibank of the US, the Banque Caisse des Commerce et d'Industrie in France, the Banque Orientale, Deutsche Bank of Germany, the Yokohama Shogin Bank of Japan, the Chosun Bank, the Chinese-Russian Dosse Bank, the Belgian Warby Bank, the Central Bank of China, etc. These historic bank buildings also have their own distinctive architectural characteristics and now are part of a group of heritage buildings in this prosperous metropolitan area. The miniature model room displays eighteen exquisite architectural models, complete with descriptions of their respective historical uses.

Once visitors leave the museum and walk down the street, they can visit and admire the actual buildings according to their interest. The museum's exhibitions therefore have an effective interplay with the various historical sites in the vicinity of the location. This design is intentional and may deepen the impression in the minds of those who visit the exhibition, giving them an interest in the history of these buildings and enhancing the experience of touring the vicinity.

There is another exhibition room in the museum. Although small and with few real artifacts, it was the highlight of my visit and the embodiment of progressive thinking: "Women Promoting Financial Development" (see Figure 5). The exhibit has several sections that explore the impact and achievements of women in finance all over the world throughout history, such as women financiers, women and fintech, women and consumption, women's banks, and women's philanthropy. This exhibition celebrates the invaluable contribution of women around the world to economic, financial, and social development, and pays tribute to those women. Tianjin is one of the top cities in China in terms of respecting women's rights; thus it is surprising but reasonable to expect that such a small museum would have an exhibition dedicated to feminism. It is hoped that museums at all levels in China will have more contents that show the power of women. 




Figure 5. The exhibition on women in finance. Photo by the author.

Bai Xue,

Victoria University of Wellington

\section{Vegetation and Universe: The Collection of Flower and Bird Paintings}

\section{Zhejiang Provincial Museum, Hangzhou}

Vegetation and Universe: The Collection of Flower and Bird Paintings is a permanent exhibition at the Zhejiang Provincial Museum displaying more than seventy paintings from China's Ming (1368-1644) and Qing Dynasties (1644-1912) to modern times (see Figure 1). Regardless of the painters' region and fame, the paintings are listed chronologically: from mid-Ming painter Zhou Zhimian, late-Ming painters Wang Duo, Yang Wencong, and Chen Hongshou, Qing painters Mei Qing, Wang Shishen, Jin Nong, Luo Ping, Hang Shijun, Li Fangying, Qian Du, Zhu Weibi, Tang Yifen, Qian Zai, and He Shaoji, to modern times with Chen Chongguang, Huang Binhong, Yu Shaosong and so on. There are even painters such as Gu Shiqi, Wang Qi, and Tong Dan, whose works are rarely exhibited in other Chinese museums. 


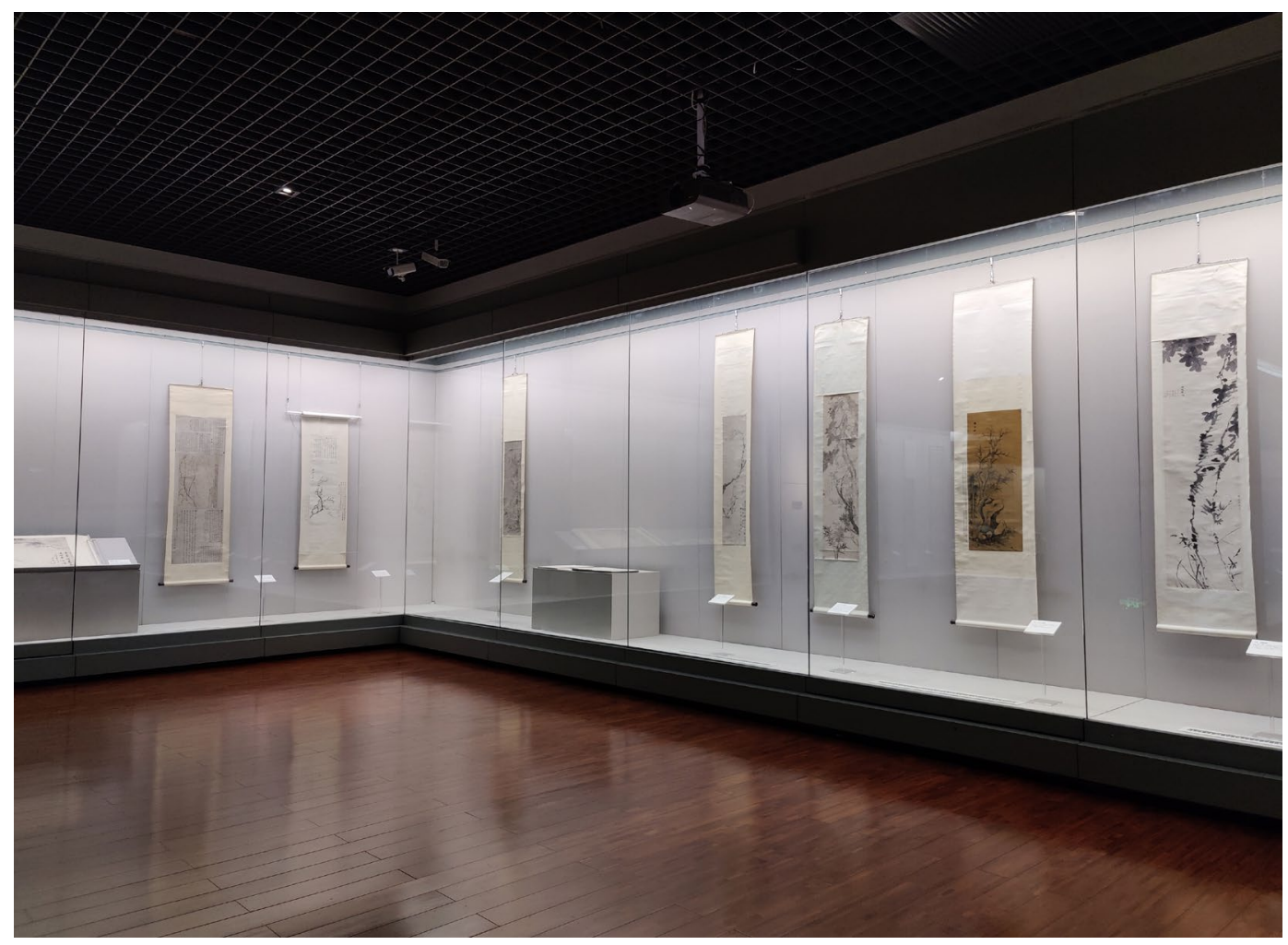

Figure 1. Exhibition Hall, Zhejiang Provincial Museum.

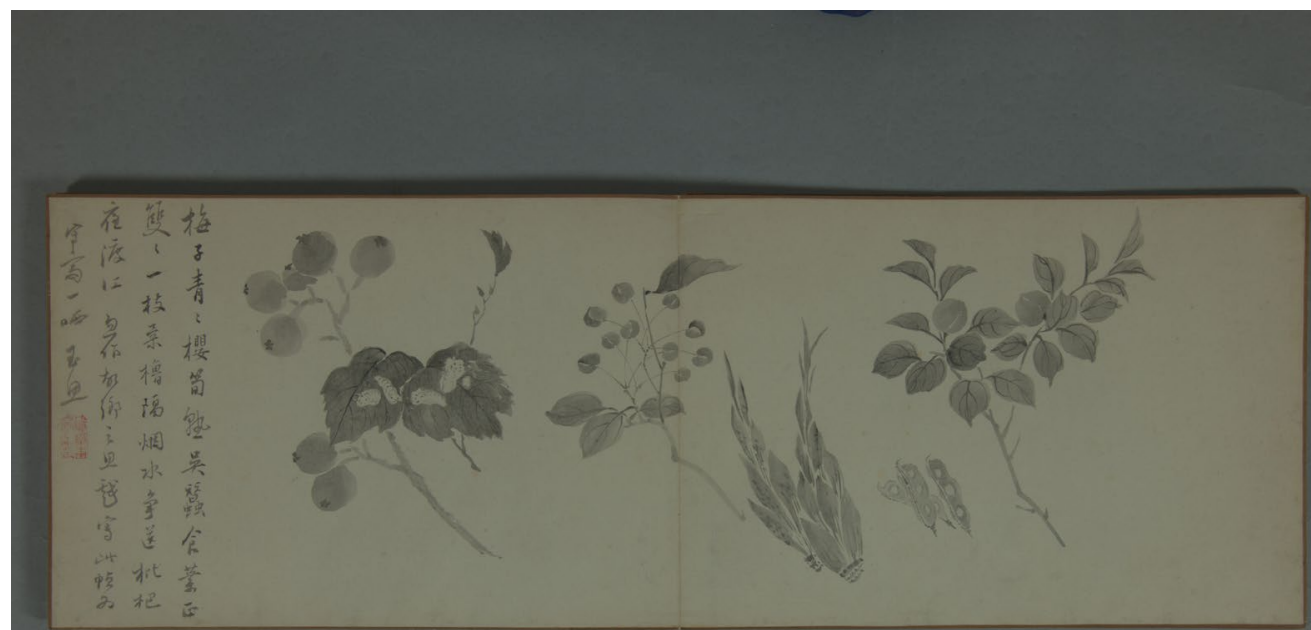

Figure 2. Qian Dong, Album of Ink Flowers, Qing Dynasty, Ink on paper, Zhejiang Provincial Museum. 
These artists were shiren (士人) which literally means literati or scholars. They put an emphasis on spiritual depth as an artistic value in works of art. Chinese literary paintings favored the style known as xieyi (寫意 freehand brushwork to catch the spirit of the object) instead of the style gongbi (工筆 realistic painting characterized by fine brushwork and close attention to details). Qian Dong's Album of Ink Flowers, for instance, did not resemble the flowers in form but used a slightly impressionistic style to express his inner feelings (see Figure 2).

The literary painters also exemplified the conflation of the arts of Shishuhua (詩書畫), which included poetry, calligraphy, and painting. This can be illustrated by the inscription of Yuan painter and art theorist Zhao Mengfu (1254-1322) in his handscroll painting, Elegant Rocks and Sparse Trees. Wen Fang observes: "Rocks like flying-white (cursive script), trees like seal script; when writing bamboo, one applies the spreading-eight method (clerical script). Only when a person is capable of understanding this, will [they] know that painting and calligraphy are basically the same" (Fang 1992: 440). The text ably explains how to draw the rock and the bamboo by the calligraphic methods, while describing the picture. The rocks eroded into weird shapes and the trees, which seem to shake, are depicted by drier brushstrokes than usual, concentrated in the center of the composition. The picture intentionally reserved a space for writing poems or inscriptions in the painting. Likewise, Qian Dong's Album of Ink Flowers also has a poem inscribed on the painting. It reads:

Green plum, cherry, and bamboo shoots are ripe;

A pair of silkworms from Wu Land are eating leaves;

A gentle scull divides the misty water;

Competing to send loquats across the river at night;

Sudden thoughts of hometown;

Playfully writes this frame for Shouzhai, laugh. (Author's translation)

梅子青青櫻笋熟, 吳蠶食葉正雙雙。一枝柔櫓隔烟水, 爭送枇杷夜渡江。 忽作故鄉之思, 戲寫此幀爲守齋一哂。

Dreary themes and plain colors may make the audience disregard this kind of exhibition. Compared to the vital role inheritance played in literati painting, Western art is preoccupied with the pursuit of innovation marked by distinctive characteristics in different periods. Stylistic change can be said to be an important criterion for appreciation in Western art, and is perhaps easier to recognize and appreciate than the painting of the Chinese literati.

Literati artists pay more attention to personal erudition and expression than similitude and the immediate attractions of superficial beauty. The esteemed poet, painter, and statesman $\mathrm{Su}$ Shi (1037-1101) discussed the scholarly landscape painting in his colophon on a landscape painting of Song court painter Song Zifang (fl. late 11th-early 12th century). It reads, "Looking at a scholar's painting is like judging the best horses of the empire: one sees how spirit has been brought out; but when it comes to artisan-painters, one usually just gets whip and skin, stable and fodder, without one speck of the superior work by [Song Zifang], which is truly a scholar's painting" (Bush and Shih 1985: 196). This explains why the tree in Huang Binhong's Ink Plum Blossom looks erratic and unrealistic (see Figure 3). This is because it aims at capturing the quintessence of the plum blossom that is in full bloom during the winter season. The characteristics of the plum blossom's growth symbolize noble and unsullied qualities that become an icon of the hermit gentleman in the eyes of the literati.

The exhibition hall is arranged according to the date of the exhibits, which complies with the chronological norms of display. A replica of Qing painter Zhu Yin's Ink Chrysanthemum has been created as a screen-like barrier to ensure an effective display of the works of art. The 


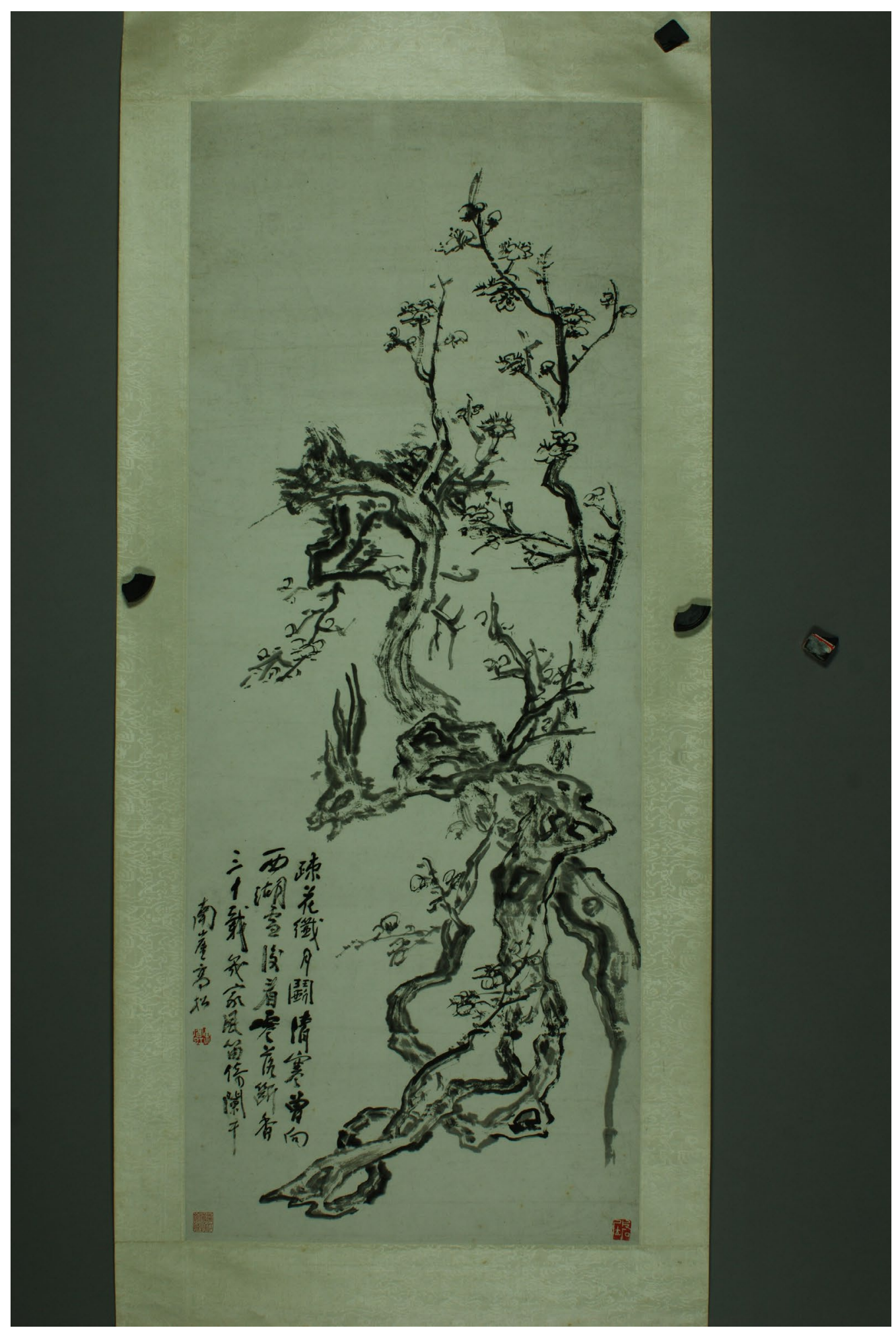

Figure 3. Huang Binhong, Ink Plum Blossom, Modern Times, Ink on paper, Zhejiang Provincial Museum. 
display effectively leads us into the world of Chinese literati in different eras. Most of them lived a simple upright life, or lived cautiously, or tried to "out-bohemia bohemia." Indeed, this demonstrates their unique view of life, that is to say, they did not care much about external needs but expressed their inner feelings through paintings, which convey the meaning and value of life, and transcend space and time.

$\mathrm{Ni} \mathrm{Na}$ Camellia Ng,

Department of Visual Studies, Lingnan University, Hong Kong

\section{REFERENCES}

Fang, Wen. 1992. Beyond Representation: Chinese Painting and Calligraphy, 8th-14th Century. New York: Metropolitan Museum of Art.

Bush, Susan and Hsio-yen Shih. 1985. Early Chinese Texts on Painting. Hong Kong: Hong Kong University Press.

\section{Three Kingdoms: Unveiling the Story}

Tokyo National Museum and Kyushu National Museum, 9 July 2019-5 January 2020, China Millennium Monument, Nanshan Museum, Wuzhong Museum, and Chengdu Wuhou Shrine, 23 January 2020-31 August 2021

The exhibition Three Kingdoms: Unveiling the Story was co-organized by Art Exhibitions China, the Tokyo National Museum, and the Kyushu National Museum to celebrate the 40th anniversary of the Japan-China Cultural Exchange Agreement (JCCEA). It was on display at the two Japanese museums in 2020 and has travelled in China since January 2021 (Figure 1). There is a long history and tradition of the two countries exchanging exhibitions, and it was not the first time for a Chinese exhibition featuring the Three Kingdoms to be shown in Japan. Back in 2008 and 2009, coinciding with the 30th anniversary of the JCCEA, the Great Romance of the Three Kingdoms exhibition toured Japan.

The Three Kingdoms (220-280 A.D.) was the historical period between the Han Dynasty (206-220 A.D.) and the Western Jin Dynasty (265-420 A.D.), when the country was largely unified. The decline of the Han Dynasty sparked a long-lasting power struggle among relentless military leaders, which lead to endless wars and turmoil. The states of Wei, Shu, and Wu became the strongest and divided the country into three kingdoms. Eventually, a powerful Wei general rose to prominence and established the Western Jin Dynasty, a new unified reign of Chinese history. The Three Kingdoms was one of the earliest periods when cultural exchanges between ancient China and Japan began. There is a rich and colorful "Three Kingdoms culture" that still resonates in both China and Japan today. This historical period that witnessed early cultural contact between the two countries with a strong legacy today seems a good fit for contemporary exhibitions to celebrate the Japan-China cultural exchanges in the twenty-first century. Both of 

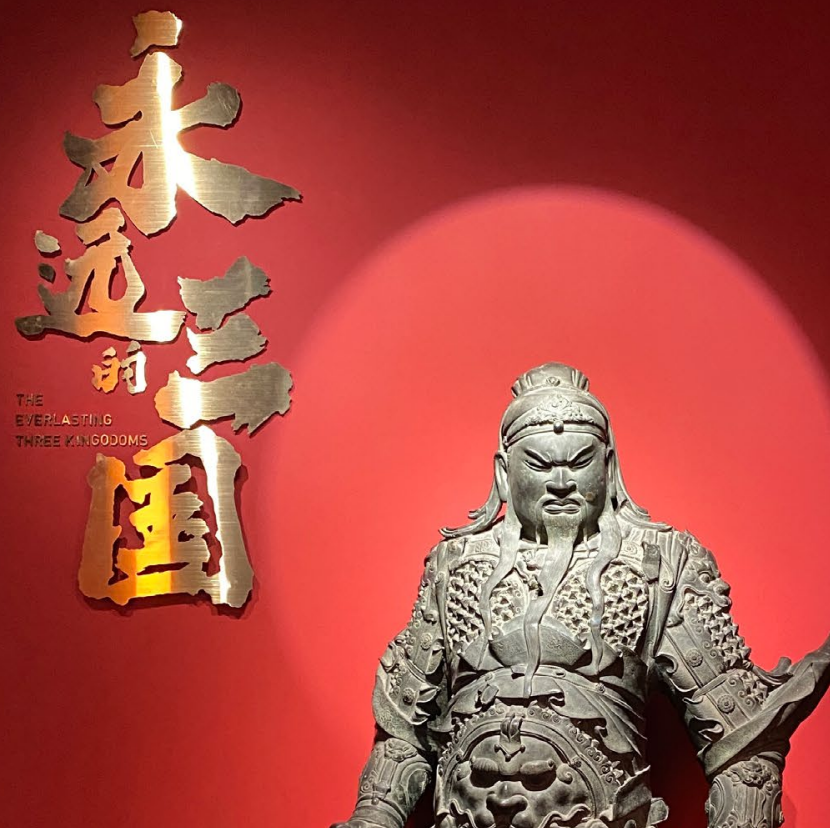

(8in

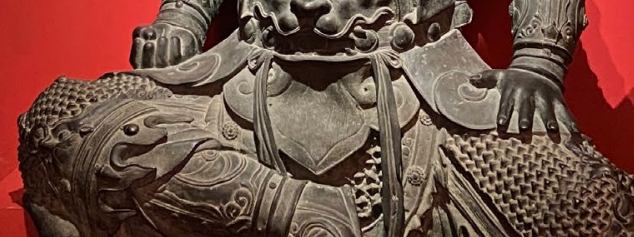

.

8
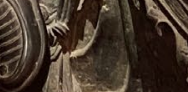
the two travelling exhibitions explored how this Three Kingdoms history and culture became beloved subjects for poetry, literature, and painting for later generations in China and Japan.

The Three Kingdoms: Unveiling the Story exhibition in Japan comprised six parts. It attempted to recreate the journey of ancient China from the unified Han Dynasty to division and ultimately reunification. The prologue generalized the rise and fall of various warlords in the Three Kingdoms period, as well their impact. The first section briefly introduced the roots of the leaders of the Three Kingdoms. The second part of the exhibition addressed the prosperity and decline of the Han Dynasty. Section three centered on the battle between the three states, showing weapons and artifacts related to famous battles. The fourth section explored the distinct cultures and customs that developed from the different environments of each state.

After that, the fifth segment featured recent archaeological finds from tombs scattered throughout their ruling areas, including burial objects from the Cao Cao Mausoleum. Cao Cao was the founding father of the Wei State and his tomb was excavated from 2008 to 2009. Finally, the exhibition ended with a brief account of the new order established by the Western Jin dynasty. In addition, the exhibition presented original pictures from the Japanese manga series based on the tales of the Three Kingdoms and one weapon recovered from the Three Kingdoms-themed computer game. Puppets from the Japan Broadcasting Corporation (NHK) program Puppet Theater: The Romance of the Three Kingdoms were also displayed to match the historical characters.

This exhibition, together with the earlier Great Romance of the Three Kingdoms exhibition, marked an important step in the curatorship of China's international exhibitions, paying attention to the turbulent transitions of Chinese history. The majority of cultural relics exhibitions going out of the country feature China as a unified country with an uninterrupted history, displaying exquisite cultural treasures from China's prosperous historical dynasties. International exhibitions focusing on the period when China was in division and chaos are rare, but not without precedent. For example, in 2004 and 2005, The Metropolitan Museum of Art (The Met) in New York held the exhibition China: Dawn of a Golden Age, 200-750 AD with loan objects from China. It featured China's Five Dynasties and Ten Kingdoms Period, when there was a convergence and divergence of cultures from the east to west and north to south of China, despite wars and chaos just as in the Three Kingdoms period. This nurtured the glorious Tang Dynasty as one of China's most prosperous periods, which was open to cultural exchanges within China and with the world.

That exhibition was curated by the Met, and this Three Kingdoms was co-curated by China and Japan. The Three Kingdoms period was positioned as a connecting link between the Han Dynasty and Western Jin Dynasty, a small chapter in the five-thousand-year history of China as a unified country, and helped demonstrate the cultural resilience and diversity of Chinese civilization. The decision to display this history with relatively fewer exquisite and artistic objects also indicates the development of historical interpretation among Chinese museums. It takes advantage of the cultural legacy of the Three Kingdoms as a bridge for cultural exchanges and mutual understanding between China and Japan today.

The Three Kingdoms exhibition attracted nearly five hundred thousand visitors in Japan. It was so successful that, after returning to China, it has toured four cities. It was on display at the China Millennium Monument in Beijing from January to June 2020, followed by the Nanshan Museum in Shenzhen for four months. It was also on show at the Wuzhong Museum in Suzhou between November 2020 and March 2021, and was then displayed at the Chengdu Wuhou Shrine until August 2021. When the exhibition was on show in Suzhou, which was an important city for the Wu Kingdom, and Chengdu, which was likewise the capital of the Shu Kingdom, both museums added exhibits from their own collections related to the history on display in the 
original exhibition, providing a more detailed account of the Wu and Shu kingdoms respectively. Therefore, this travelling exhibition took on strong regional characteristics at each stop, making it more relevant to local visitors.

However, it is a pity that those Japanese artifacts displayed parallel with Chinese objects in Japan did not travel to China. Most Chinese visitors were unaware of the exhibition as a China-Japan cultural exchange product, as well as the impact of the Three Kingdoms culture in Japan. While touring China, the section on the battles between the three states was removed from the exhibition. Instead, it presented them separately, thus weakening the connection between them. Despite such imperfections, Three Kingdoms remains a praiseworthy and pioneering international exhibition for Chinese museums.

Mingyuan Jiang,

Fudan University, Shanghai

\section{Tempest}

Tasmanian Museum and Art Gallery (TMAG), Hobart, 10 June-20 November 2016

Shakespeare's play The Tempest was the formative inspiration for TMAG's exhibition Tempest, but it was not a purist retelling. Tales of ships on stormy seas were interpreted through objects and artworks from TMAG's collections while simultaneously alluding to Tasmanian history. The interpretive approach provoked curiosity, as it encouraged individual experience rather than offering one dominant reading. Tempest claimed top prize at the Australian Museum and Galleries National Awards in 2017. I would say much of this success is due to its innovative approach to interpretation; therefore, this review primarily focuses on the exhibition's interpretive methods and the outcomes from a viewer's perspective.

As you entered this exhibition, you discovered a re-imagining of Prospero's library. This all-consuming display included piles of books, a Victorian staircase, cabinets full of curiosities; and from above you were encircled by flying books (see Figure 1). Russell Staiff (2014) notes that a sensorial approach to exhibition interpretation allows audiences to leave the known world behind them and enter another realm. I found that Prospero's library set the scene and successfully transported you into the magical world of Tempest.

In interpretation literature, a thematic approach to developing exhibition content is deemed essential. Steve Slack (2021) exclaims that when themes are weak, the impact on the audience is severely reduced. The thematic interpretation panel in Prospero's library was important as it provided an access point to those who were not aware of the Shakespearian connection. It identified the core themes of the exhibition: storms, magic, tragedy, discovery, and romance. The arrangement of objects in the exhibition was thematically positioned for maximum impact. The use of repetition highlighted the themes, removing the need for textual clarification. For example, in one section, you entered into the brink of a storm, an effect that was achieved by a compilation of stormy sea and shipwreck paintings (see Figure 2).

Decisive placement of paintings and artefacts ensured that the galleries did not become overcrowded. There needed to be enough objects to emphasise the themes without making the 


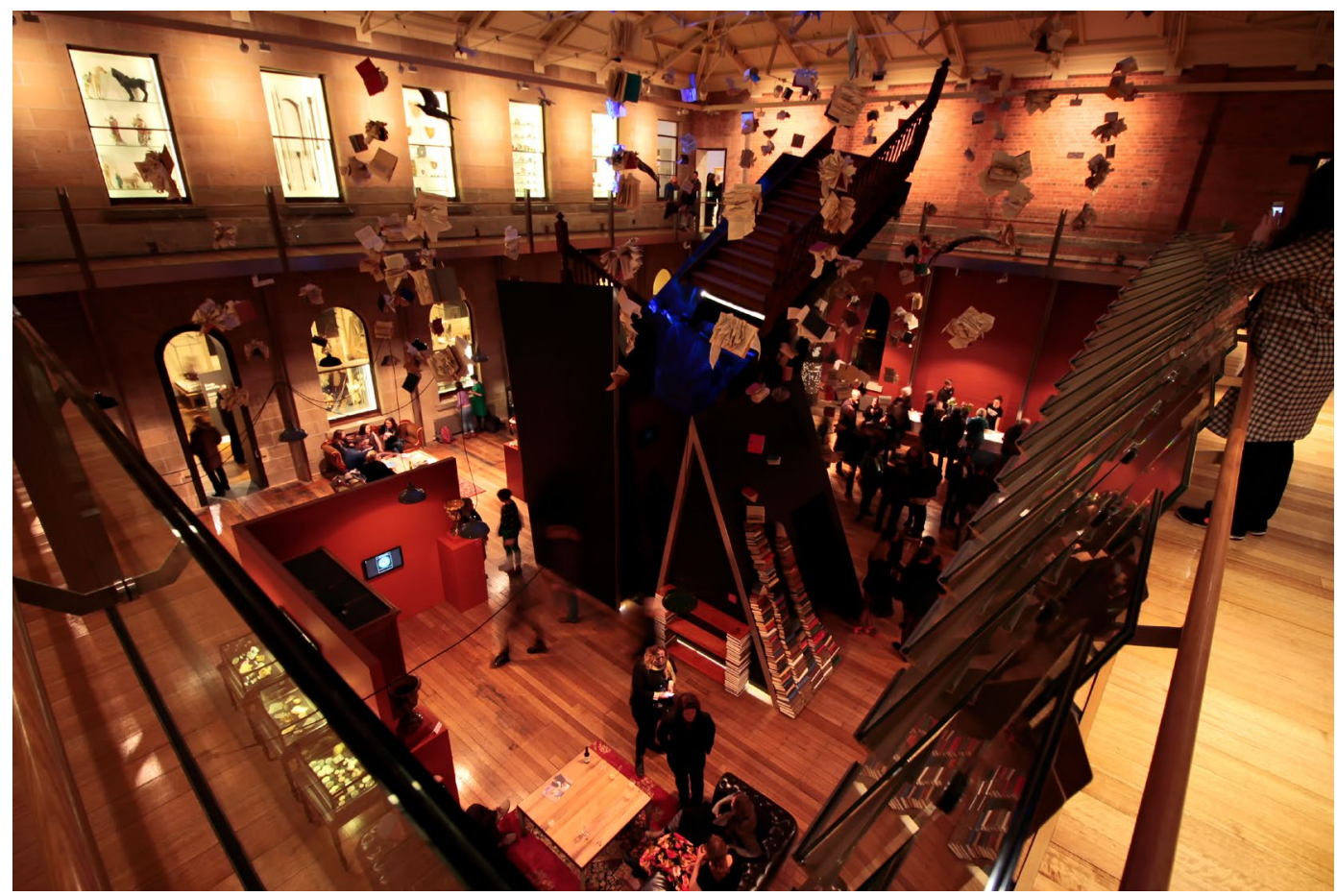

Figure 1. Tempest installation view. Tasmanian Museum and Art Gallery, Hobart, 2016. Courtesy of Tasmanian Museum and Art Gallery.

audience feel overwhelmed, as can happen when entering a crowded antique store. By allowing space for contemplation, it gave room for individual engagement. This approach allowed visitors to create their own connections and identify with whichever object they were most drawn to. There were no rules, or over-directed pathways, in terms of how you interacted with the content, nor any sense of hierarchy. In the past, museums tended to foster a top-down approach to interpretation, but the new museology has advocated a reciprocal engagement (Vergo 1989).

The layout of the exhibition enacted a journey. Artworks were mounted in pop-up locations throughout the whole building - some in stairwells and others in the permanent exhibition galleries, like an artist's intervention. Extending the exhibition into other parts of the gallery stimulated exploration and disrupted the notion of a linear exhibition, as an individual could forge their own route through the galleries. This curatorial approach challenged rigid museological traditions of classification and genre separation. The encouragement to explore was fitting for an exhibit that related the experiences of travellers and settlers weathering life on an island in the storm-tossed Southern Ocean.

TMAG is in a unique position as it is one of few institutions in Australia that is both an art gallery and a museum. Tempest brought historical objects and artworks from the collections into a theatrical fantasy. The dynamic juxtaposition of artefacts set alongside historical and contemporary artworks created space for the objects and enabled them to do the interpretation rather than relying on excessive textual explanations.

The exhibition reflected on Tasmania's important maritime history and also spoke to its island mentality (Harwood 2011). While Tempest did reference Shakespeare, it also referenced local histories and experiences, which made it more relevant for Tasmanian audiences; this exhibition, 




Figure 2. Model ship and maritime paintings featured in Tempest. Tasmanian Museum and Art Gallery, Hobart, 2016. Courtesy of Tasmanian Museum and Art Gallery. 
the institution, local history, and Tasmania's geography were intrinsically linked. As a visitor, I felt that Tempest provided an enriching experience, as there were many layers to be uncovered, and had these local connections not been established, it would not have been so effective or relevant (Simon 2016).

Objects housed in TMAG's collections, and in other institutions, are at risk of being irrelevant if they are not engaged with (Stam 1993). Staiff (2014) argues that there is a necessary duality between people and objects, each needs the other for meaning to be actualised. We can see this in Tempest, where maritime art and other varied collection items found new meaning through their incorporation into an engaging story in which the audience gained a greater sense of place due to local references and connections.

The curatorial approach was playful, breaking structured and linear narratives that restrict participation and boundaries between art and history. Instead, Tempest encouraged curiosity and intrigue, enticing the audience to find their own way through the entire gallery. The textual interpretation was light, as meaning was conveyed mainly through the objects themselves. Dynamic exhibitions like this allow the audience to feel something; they show as well as tell.

\section{Ashleigh McLarin,}

Victoria University of Wellington

\section{REFERENCES}

Harwood, Andrew Geoffrey. 2011. “The Political Constitution of Islandness: The 'Tasmanian Problem' and Ten Days on the Island” (PhD diss., University of Tasmania).

Simon, Nina. 2016. The Art of Relevance. California: Santa Cruz.

Slack, Steve. 2020. Interpreting Heritage: A Guide to Planning and Practice. Abingdon: Routledge.

Staiff, Russell. 2014. Re-Imagining Heritage Interpretation: Enchanting the Past-Future. Surrey: Ashgate.

Stam, Deirdre C. 1993. "The Informed Muse: The Implications of 'The New Museology' for Museum Practice." Museum Management and Curatorship 12: 267-283.

Vergo, Peter. 1989. The New Museology. London: Reaktion Books.

\section{Wonders from the South Australian Museum}

\section{South Australian Museum, Adelaide, 10 April-8 August 2021}

Located in the City of Adelaide, the South Australian Museum holds collections of both national and international significance. This institution states that its purpose is to inspire a sense of wonder and curiosity in people about life on Earth). The exhibition Wonders from the South Australian Museum ran from 10 April to 8 August 2021. It presented a rare opportunity to explore objects from its extensive collection of more than four million specimens and material cultural items, some of which have never been viewed by the public before. The museum urged the visitor to leave this exhibition with a deeper understanding of the history, cultures, and natural wonders that are held within its vast collections. This also included understanding part of the museum's own history, through its poster collection (see Figure 1). 


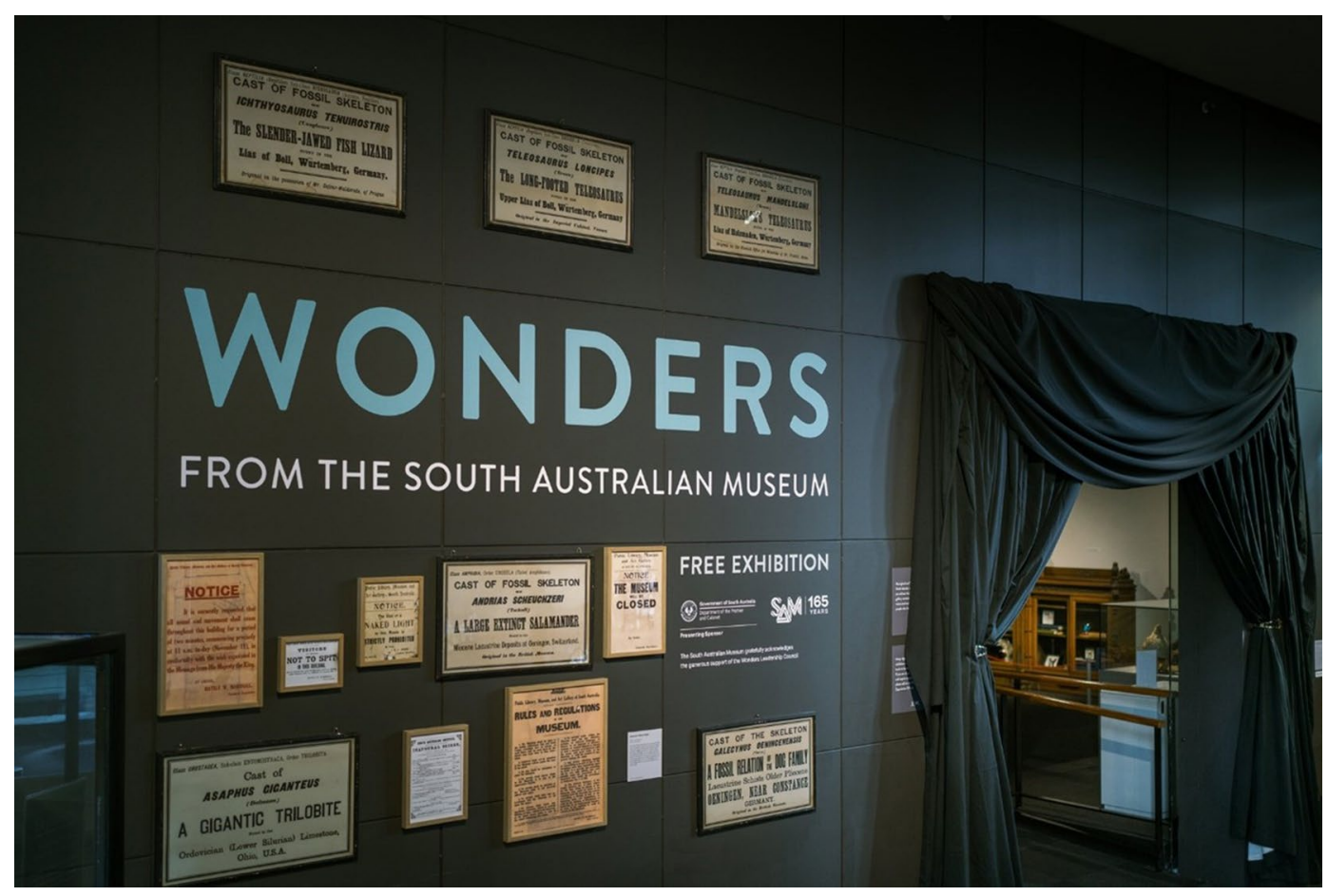

Figure 1. These posters are a part of the museum's history in communicating with its visitors. Courtesy of Israel Baldago and the South Australian Museum.

The exhibition was put together by guest curator Nat Williams from the National Library of Australia, in Canberra, where he is the first James and Bettison Treasures Curator. It was designed to appeal to people of all ages, and admission was free, due to the sponsorship of the Department of the Premier and Cabinet in South Australia. The 165 objects on display represented a broad snapshot of the richness and diversity of the collections held by the museum since it first opened its doors in June 1856 (Wonders exhibition 2021). The selected number of objects on display cleverly reflected this important 165th anniversary. In having a guest curator, however, the resident curators missed an opportunity to collaborate across their different disciplines on this significant anniversary.

The exhibition was divided into ten sections representing Aboriginal artifacts, imperial power, deep space and time, the natural world, extinction and loss, global objects, scrimshaw pieces, and the Wunderkammer, a cabinet of curiosities first used to house rarities and curiosities of private collectors. The exhibition was itself a walk-through Renaissance Wunderkammer, taking the visitor on a journey through space and time and leaving them pondering the objects both large and small that hung on the walls or were displayed in various antique museum display cabinets around the room. To indicate the impressive temporal range of the exhibition, it contained objects as old as the Fragment Nakhla Meteorite from Mars to as recent as a Schrimshaw Walrus Tusk collected in 1958. One eye-catching object is the Persian Metal Helmut, thought to be made in either Indian or Iran. (see Figure 2). Another is the 1980s Phantom Shield from Papua New Guinea, representing the museum's Aladdin's cave of objects from all over the globe (see Figure 3).

John Choate, one of the founders of the Metropolitan Museum in New York City in 1870, suggested that collections on display "should be educational, informative and entertain people; 


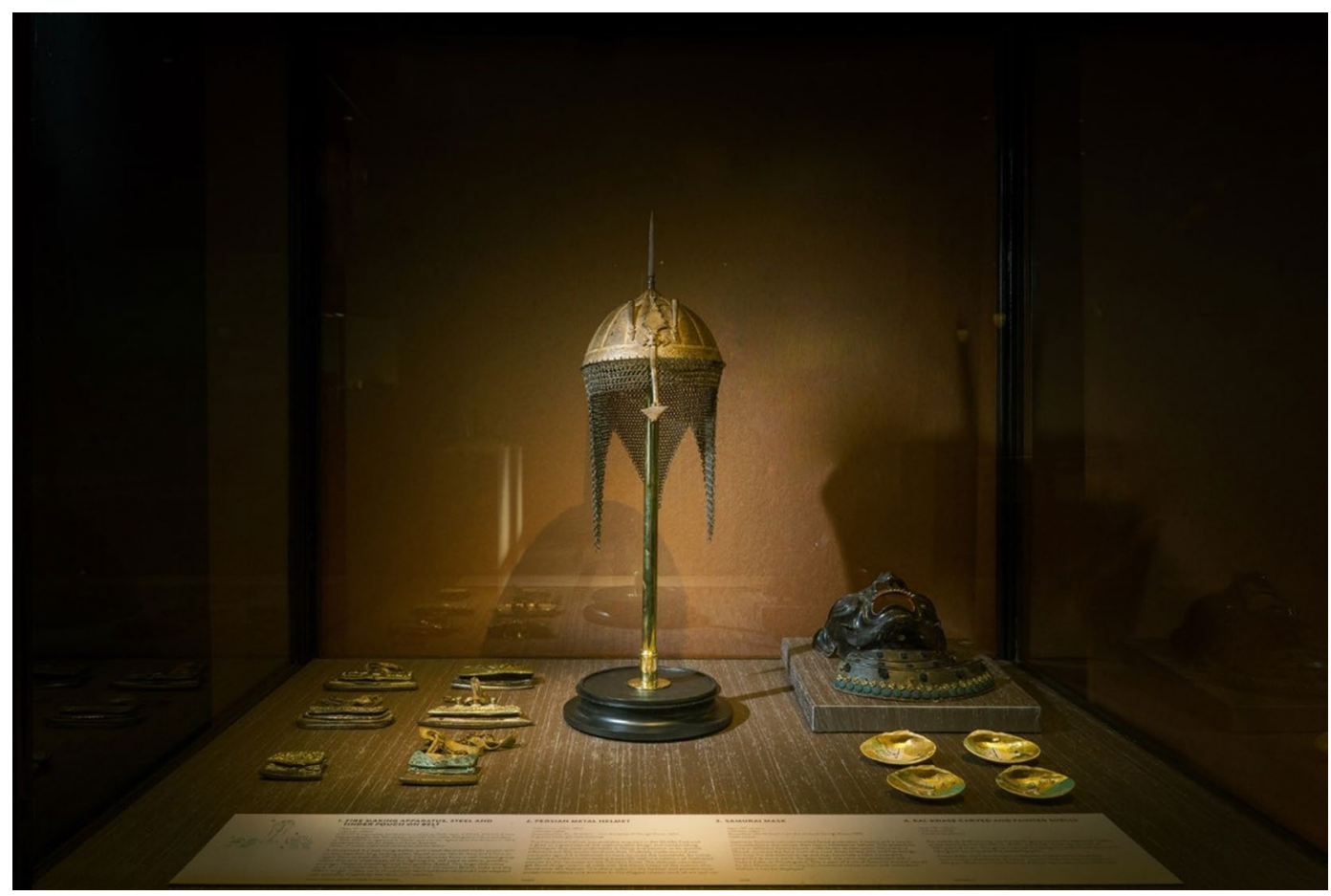

Figure 2. Persian Metal Helmet, Indian or Iran, 1750-1850. The delicate gilt floral design seems at odds with the fierce intent of the warrior who would wear the helmet Courtesy of Israel Baldago and the South Australian Museum.

the displayed objects should be illustrative of all the branches found in the history of the arts" (Bradburne, Perlov and Simon 2011: 87). This exhibition certainly lived up to this statement. The visitor was invited on a world tour through the clever use of such items as paintings, textiles, wildlife, science, and maps. It charted the natural world and displayed remnants of species now lost, both in the past and more recently in the present.

Importantly, the museum sits on Kaurna land at Tantanya, the place of the red kangaroo, and the Aboriginal cultural objects on display were indicative of a rich and sophisticated culture that continues today. The visitor was reminded that today natural history museums must contend with the difficult legacy of objects unlawfully collected during European imperialism and have an active voice in the growing conversations about their return.

The overall area was surprisingly small for the display of so many objects. The clever use of antique museum display cabinets allowed for multiple pieces to be exhibited side by side, while the artworks and wall hangings drew the eye to various corners of the room. Although the museum and the curator told the story of this exhibition through the labels, the introductory panel was not immediately obvious. This could have led the visitor to overlook a narrative that serves to give coherence to an otherwise highly eclectic collection.

The lighting, as one would expect, was quite low in places in order to offer a variety of tones to the visitor. However, this meant that some labels were a little difficult to read. The positioning of labels above some display cabinets required one to lean across a surface that was marked "do not touch." 


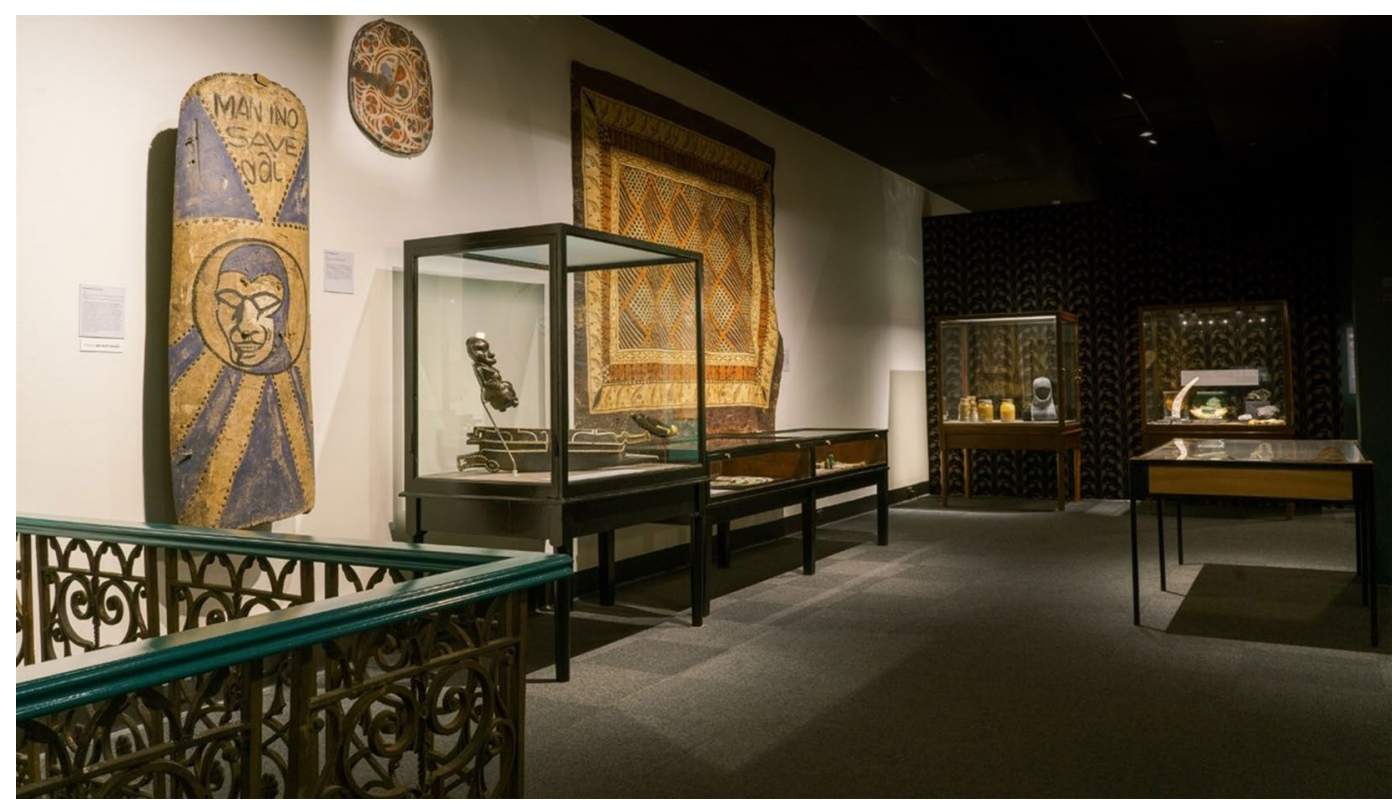

Figure 3. Phantom Shield from Papua New Guinea and other objects. Courtesy of Israel Baldago and the South Australian Museum.

The overall experience was, however, a delightful wander through time to explore the magnificent pieces from the various collections gathered over the life of the museum. This exhibition educated and entertained in equal measure. It was an opportunity for young and old to take a journey around the globe. Visitors were invited to experience many different cultures, trades, craftsmanship, and artistic skills through objects. While using traditional museum practices to present these wonders, the curator created the exhibition in a way that left the visitor inspired and wanting more. It was an immediate reminder of the sense of wonder that can be generated by experiencing tangible traces of the past.

\section{Sandra Kearney,}

Flinders University

\section{REFERENCE}

James Bradburne, Diane Perlov, and Nina Simon. 2011. “The Museum of Jurassic Technology." Exhibitionist 87. 


\title{
Brett Graham: Tai Moana, Tai Tangata
}

\author{
Govett Brewster Art Gallery, New Plymouth, 5 December 2020-2 May 2021 \\ (Link to virtual tour: https://govettbrewster.com/virtualtours/)
}

\author{
Ko te mahi a te tamariki, he wāwāhi tahā \\ The work of children is to disrupt the status quo
}

Whakataukī, or proverbs, serve to steer discussion about issues that matter. The whakatauki above illustrates the intent of Brett Graham (Ngāti Koroki Kahukura) within his recent exhibition, Tai Moana, Tai Tangata, held at the Govett Brewster Art Gallery in New Plymouth from 5 December 2020 to 2 May 2021. ${ }^{1}$ New Plymouth is a coastal town in New Zealand's North Island, where natural gas and farming fuel its economy. The area has a rich, dynamic, and uncomfortable Māori and colonial history.

Tai Moana, Tai Tangata belongs to a powerful genealogy of contemporary Māori art that challenges the colonial status quo through their chosen media. Brett Graham is a mokopuna of Tainui, a descendant of Pākehā heritage, and is of distinguished artistic lineage-his father is the renowned artist, Fred Graham ONZM (New Zealand Order of Merit). This mixed media exhibition is Graham's outstanding contribution to the evolution of Māori creativity and cultural justice.

Graham continues to disrupt the practice of non-Māori recording Māori experiences through the arts. His exhibition describes the enduring relationships between Tainui and Taranaki peoples in the midst of the invasion of their lands undertaken by the British colonial administration. For Māori audiences, including myself, his work provokes us to reconnect to our own histories, our own stories, our own experiences. He literally carves out spaces in his exhibition for this reclamation to occur. Regardless of background, the audience can't help but be provoked into discussion about what they are confronted with.

In its final week of showing at the Govett Brewster, our whānau decided to make the journey to the exhibition. We wanted our own mokopuna to experience the artworks for themselves. We did not expect the theme of disruption to be made as personal as it was.

Upon entering the gallery, we were immediately immersed in our own history. Ahead of us lay the black-on-black carpeted staircase, Purutapu Pōuriuri (Black Shroud) (see Figure 1). The audience is invited to proverbially don the black carpet and mourn their departure from the colonial gaze. Visitors literally trample colonial flags as they move into a world where Taranaki and Tainui iwi narratives are privileged. Then, our eyes were drawn toward an imposing and exquisitely carved niu pole, Cease Tide of Wrong-Doing that reaches ten meters into the air, slicing through the multilevel gallery space. Niu poles were used for ceremonial purposes, and were designed for flying flags. Whakarare carving patterns on the niu pole weave an unbroken channel tethering earth to heaven for transmission of karakia. The niu pole is a stoic reminder to retain and grow our heritage, and to have faith in our ability to choose for ourselves how we tell our stories (see Figure 2).

A glimpse of a bleak dystopian future features in three digital pieces, titled Te Namu, Ohawe, and Manukau. Each is a CGI animation based on significant pā sites in the Taranaki and Tainui regions. They tell the sordid story of raupatu, of confiscation of Māori land, and the theft of iron sand from the coastline. The air within the exhibition space shakes with a groan: the soundscape is reminiscent of a shipwreck being forced out of its comfortable groundedness by the impending tide. 

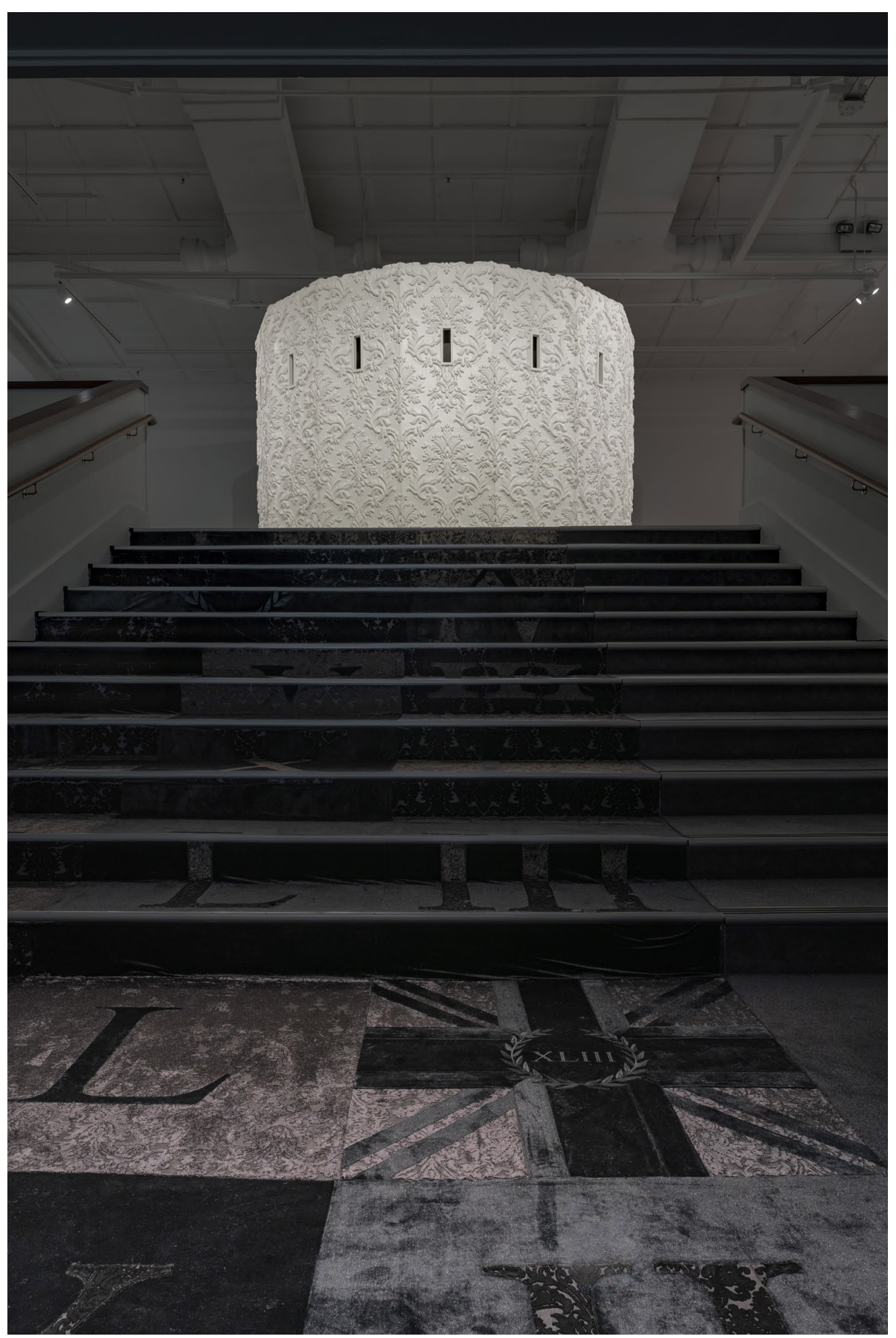

Figure 1. Purutapu Pōuriuri (Black Shroud), carpeted staircase leading up to the embellished gun turret sculpture, O’Pioneer. Courtesy Neil Pardington (Kāi Tahu, Kāti Mamoe, Ngāti Waewae). 


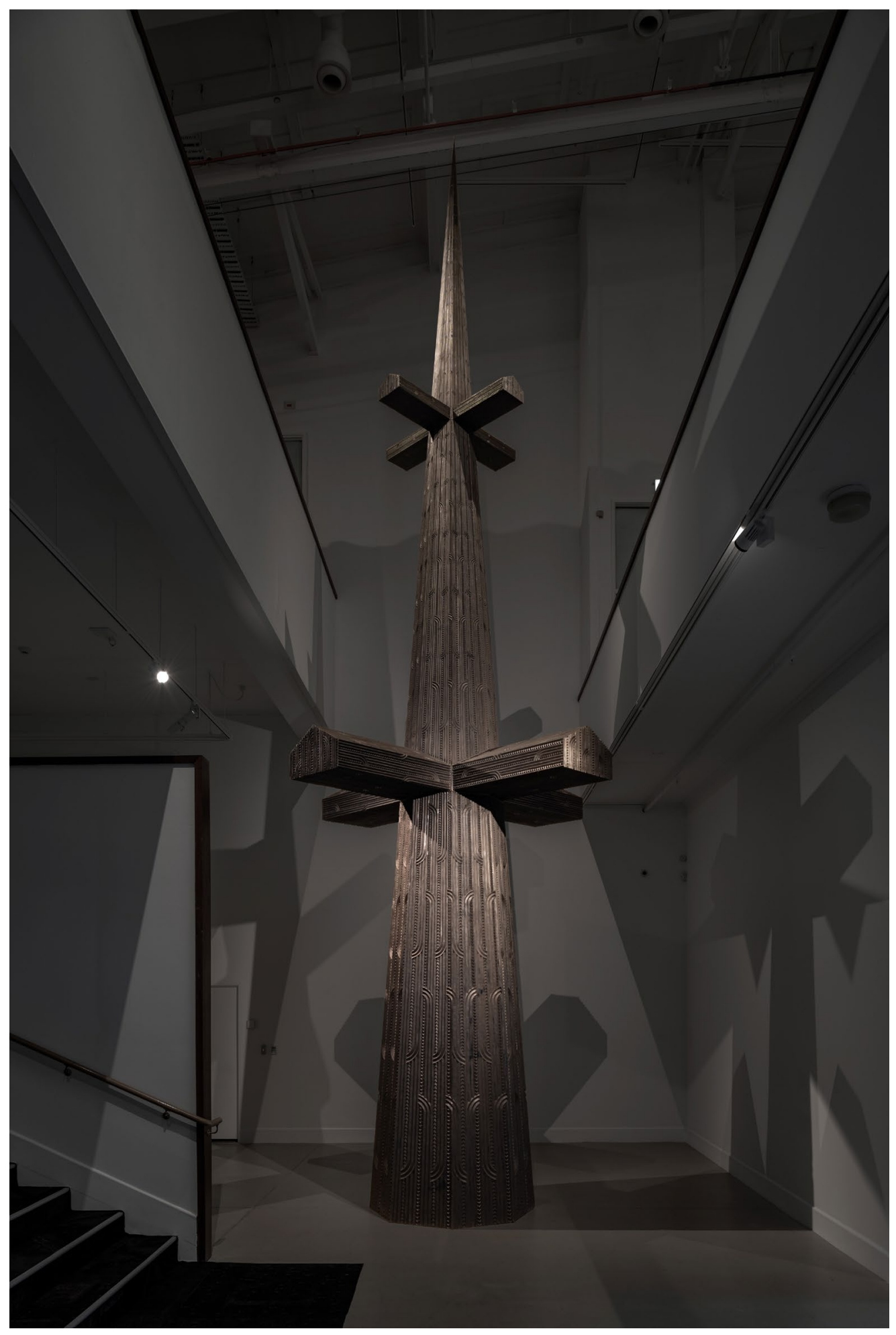

Figure 2. Cease Tide of Wrong-Doing, niu pole from Brett Graham's exhibition Tai Moana, Tai Tangata. Courtesy Neil Pardington (Kāi Tahu, Kāti Mamoe, Ngāti Waewae). 
Positioned elegantly at the top of the staircase sits O'Pioneer, an embellished gun turret (see Figure 1). It has the appearance of a delicious, fondant-covered wedding cake, a symbol of union. But a union of whose arrangement, and to whose benefit? Upon closer inquiry, the sculpture references two remnant gun turrets from Pioneer, a nineteenth century paddlesteamer warship. The turrets are still on display, still revered in Meremere and Ngāruawāhia, small townships nestled by the Waikato River that form part of the Tainui region. The colonial experience in these townships, and many others, was brutal and the effects ongoing.

Next, a wagon-like sculpture comes into view. It is Maungārongo ki te Whenua, Maungārongo ki te Tangata, a carved pātaka on worn wagon wheels (see Figure 3). The carving style references the Motunui panels, carvings that were illegally sold to collector George Ortiz in 1972, repatriated to Taranaki in 2015, and now housed at Puke Ariki museum in New Plymouth. A well-heeled pātaka is a symbol of manaakitanga, of service and care of people regardless of who those people might be. Graphite dust lies in a thick layer on the pātaka. It is a tense reminder of the iron sands stolen as a result of colonial exploitation of Indigenous peoples' landscapes. It is a tragic repayment to tāngata whenua who demonstrated hospitality toward colonial soldiers, while the peaceful Taranaki settlement of Parihaka was invaded. Looking across a gap in the gallery space, we spy Grande Folly Egmont, another gun turret. It is in the form of a weatherboard tower featuring horizontal gun slits, and painted an ironic shade of ivory. Its shape is reminiscent of a Dalek from the popular TV series, Doctor Who, and a reminder of the infamous Dalek catchphrase, "Exterminate! Exterminate!” (see Figure 3).

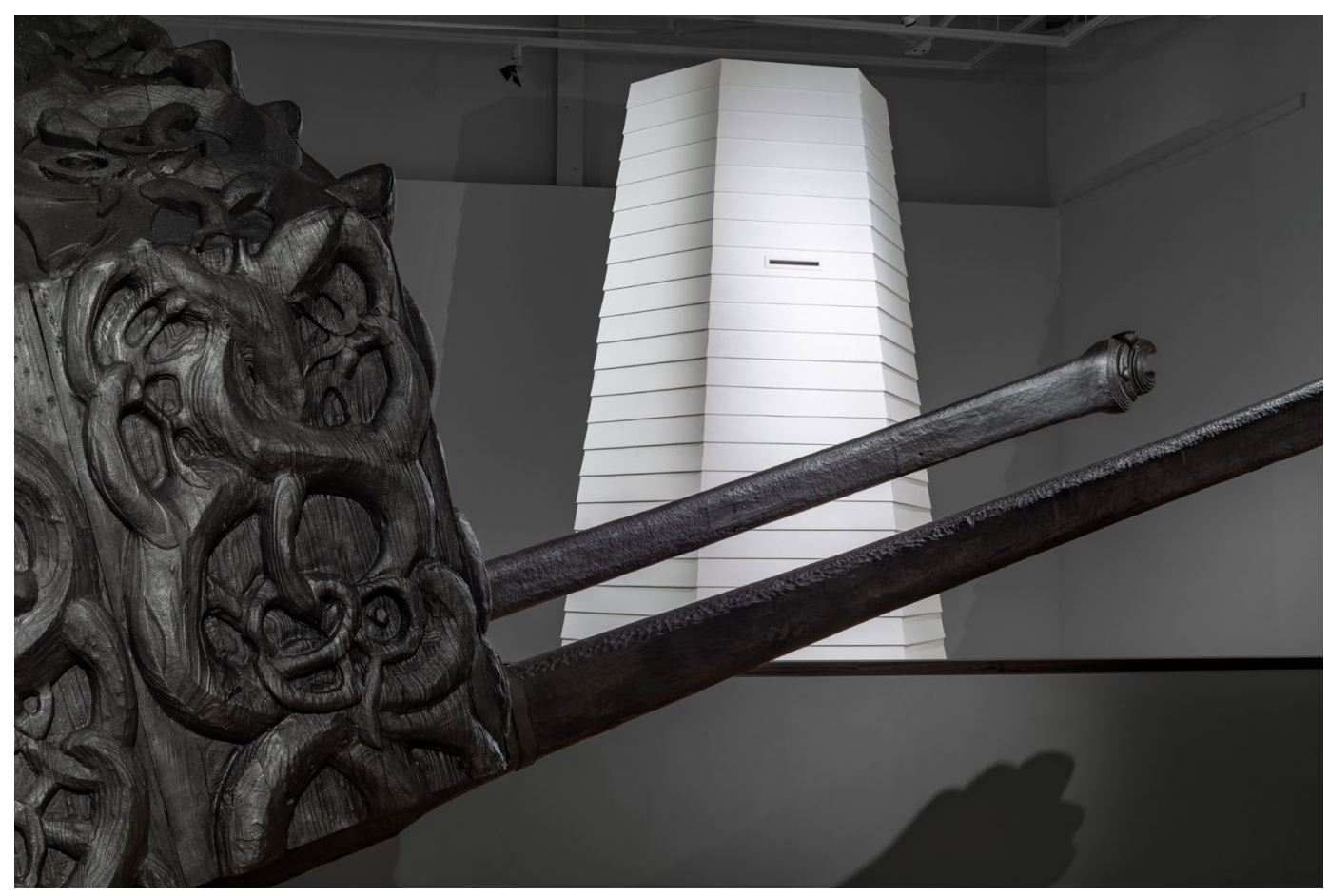

Figure 3. Maungārongo ki te Whenua, Maungārongo ki te Tangata, carved pātaka (foreground). Grande Folly Egmont, weatherboard gun turret (background). Courtesy Neil Pardington (Kāi Tahu, Kāti Mamoe, Ngāti Waewae). 
The politically charged and disruptive orientation of Tai Moana, Tai Tangata is intertwined with the bilingual labeling of the artworks. Often te reo Mãori is used in a gallery or museum in a transactional manner-a translation of the English content into the Māori language. However, Graham sidesteps this orientation with his critical awareness that many concepts in Māoridom defy simple translation. Instead, he rejects transactional forms of translation altogether. For example, whakataukī and tongikura are placed throughout the exhibition. Te Ingo Ngaia (Manukorihi, Ngāti Tairi, Ngā Māhanga, Ngāti Manuhiakai, Waikato-Maniapoto, Ngāti Hikairo), an educator, composer, and herself a mokopuna of Taranaki and Tainui, composed the elegant text. The exhibition labels become kura huna-hidden gems_-for speakers of te reo Māori, but in this case they are cleverly hidden in plain sight. Their presence is a direct link to our ancestral wisdom: a thrilling and poignant dive into our prophecies and values.

If the power of children is to be inquisitive, curious, and to challenge taken-for-granted comforts and privileges - as the opening whakatauki suggests-then who better to deliver this reminder than a mokopuna of Tainui and Taranaki people? Tai Moana, Tai Tangata is a potent reminder of our collective responsibility to address the ongoing devastating impacts of colonialism. This is complex, dangerous, and ultimately rewarding work. As Puawai Cairns (2020) states, "we are searching for a future where lived experiences of being Māori, where our relationship to our material culture, is respected and honored in museums on our own terms." This exhibition is a brilliant manifestation of this vision.

Riria Hotere-Barnes,

Ngāti Maniapoto, Te Aupōuri, Te Rarawa, Ngāti Wai

\section{NOTES}

1. Brett Graham is an Arts Foundation Te Tumu Toi laureate who received the prestigious My Art Visual Art Award in 2021.

\section{REFERENCE}

Cairns, Puawai. 2020. "Decolonise or indigenise: Moving towards sovereign spaces and the Māorification of New Zealand museology." Te Papa Blog, 10 February. https://blog.tepapa.govt.nz/2020/ 02/10/decolonise-or-indigenise-moving-towards-sovereign-spaces-and-the-maorification-of -new-zealand-museology/.

\section{The "Inbetweenness" of the Korean Gallery at the Musée Guimet, Paris}

From the late 1990s, the South Korean government's support for the establishment of permanent Korean galleries in museums across the globe has opened a new phase in the representation of Korean culture on the international stage. The "Korean gallery" in international museums here refers to a permanently displayed independent space with a comprehensive Korean collection. This review assesses the establishment and development of the Korean gallery in Musée 


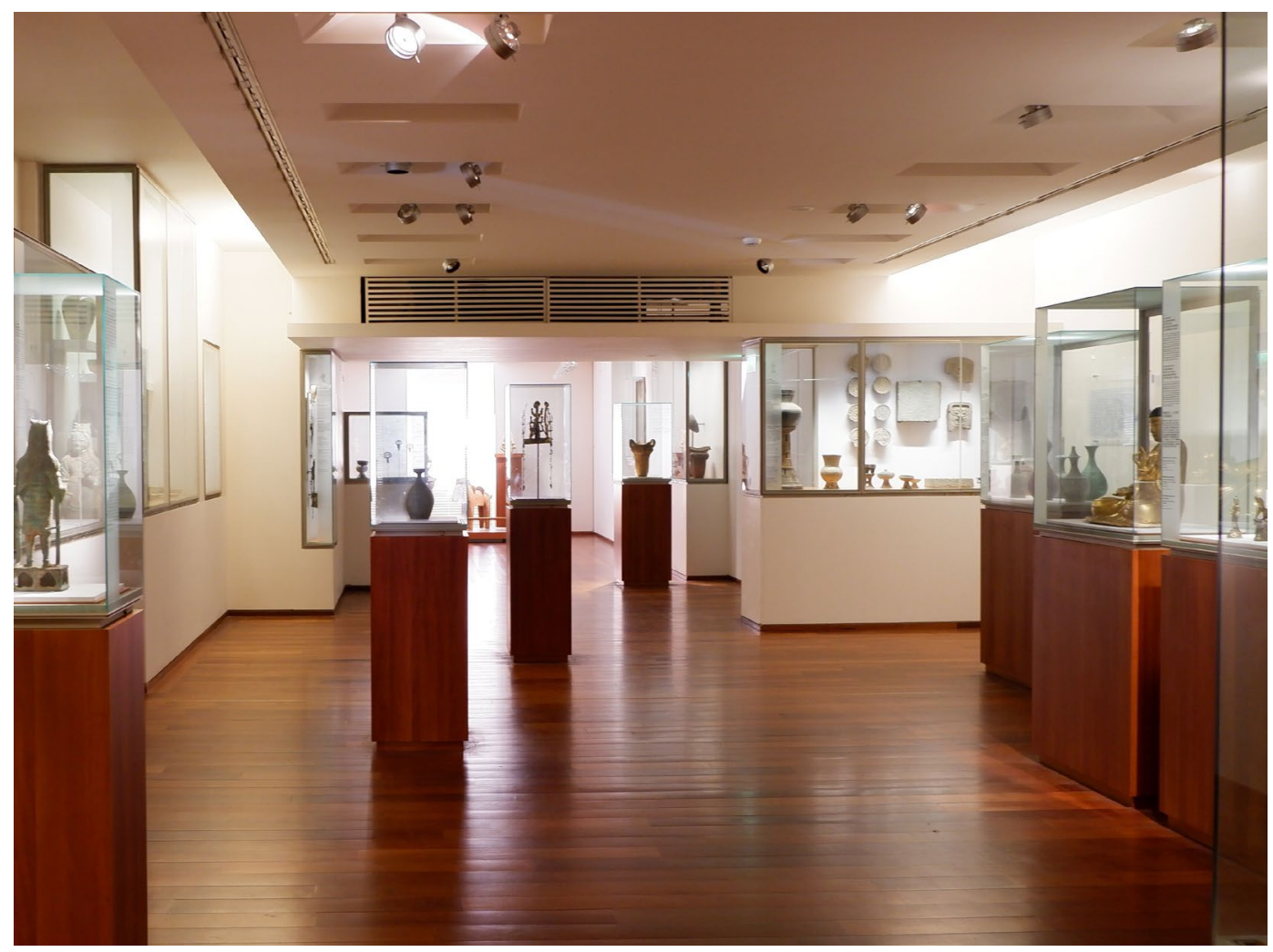

Figure 1. The main Korean gallery space of the Musée Guimet (photo by the author).

Guimet-France's National Museum of Asian Art-in Paris (see Figure 1) over time. It argues that the Korean gallery is neither a perpetual, static representation of Korean culture nor a structured form of display of Korean cultural materials; rather, it is an "inbetween" space.

First opened in 1889, after the transfer and relocation of the Louvre's Asian art collections, the Musée Guimet was reborn as one of the world's largest Asian art museums (The Korea Foundation 2002: 203-204). The museum's Korean gallery was the first in Europe, opening in 1893. The Musée Guimet's closure in 1919 because of World War I, the re-opening of the Korean gallery in 1970, and the gallery's refurbishment with the support of Korean institutions in 2001, indicate the shifting historical contexts of and influences on the gallery. It is now one of the principal instituitions supported by the Korea Foundation (founded in 1991 and an affiliate of the Korean Ministry of Foreign Affairs) as part of its cultural diplomatic mission and practice.

The notion of material culture's "inbetweenness," in-between the cultural origin and what is its displaced place, has recently been explored from an object's point of view (Dudley 2017, 2021). This idea probes not only things as "material metaphors that evoke, express or represent ideas" but also their actions in the world through the involvement of agency (Basu 2017: 2). Broadening "inbetweenness" out from particular artifacts to collections and gallery display as a whole, this review attempts to reflect upon two phases of "inbetweenness" in the life of Musée Guimet's Korean gallery. It focuses on the involvement of specific "agencies" in particular historical moments since the inception of the gallery.

The first dimension of "inbetweenness" relates to the developers involved in making the Korean gallery. The present gallery was not wholly established either by the museum or by South 
Korean cultural institutions. Instead, it is a result of the entangled influences of both. The collection, and the standards of selection by which it grew, were pioneered by and through the eyes of the French collectors, Charles Varat (1843-1893) and Collin de Plancy (1853-1922). Varat was a French anthropologist who visited Korea in 1888 with a mission from the French Ministry of Public Education and Fine Arts to collect materials that effectively represented Korean identity as one of the Oriental cultures (text panel 2019). It was mostly the folkloric objects chosen by Varat that became part of the exhibition in the Paris World Exposition 1889 as well as in the first Korean gallery, which was called Korean Religion and Ethnography, in 1893 (Shin 2013: 54). De Plancy (1853-1922) was the first French diplomat posted to Korea from 1888 to 1891. He supported and collaborated with Varat in identifying Korean cultural identity, and Plancy himself collected Korean materials (which he contributed to the museum) during his stay and later at the request of Émile Guimet (a founder of the Musée Guimet). He also led the building of the Korean pavilion in the World Exposition in Paris in 1900 (text panel 2019). He was a key person in the construction of the early Korean image abroad. These individuals clearly focused on the materials that represented Korea to them (Shin 2013), leading to the predominant display of folkloric or Orientalistic materials in the early gallery exhibitions and contributing to "the singular culture of a kingdom" in representations of Korea in France (text panel 2019), despite the Korean national heritage materials left in the storeroom.

The exhibition space was subsequently refurbished with the support of the Korea Foundation. This included an enlargement of the gallery space to $360.35 \mathrm{~m}^{2}$ prior to the re-opening in January 2001. As part of this refurbishment, the content and significance of the existing but hitherto un-displayed early Korean collection (see Figure 2) were re-investigated (The Korea Foundation 2002: 190-203). As a result, one thousand objects previously in storage were put on display. This was the result of a process that was shaped directly by South Korean cultural diplomatic policy and its aim to expand cultural exchange between South Korea and France by introducing Korean

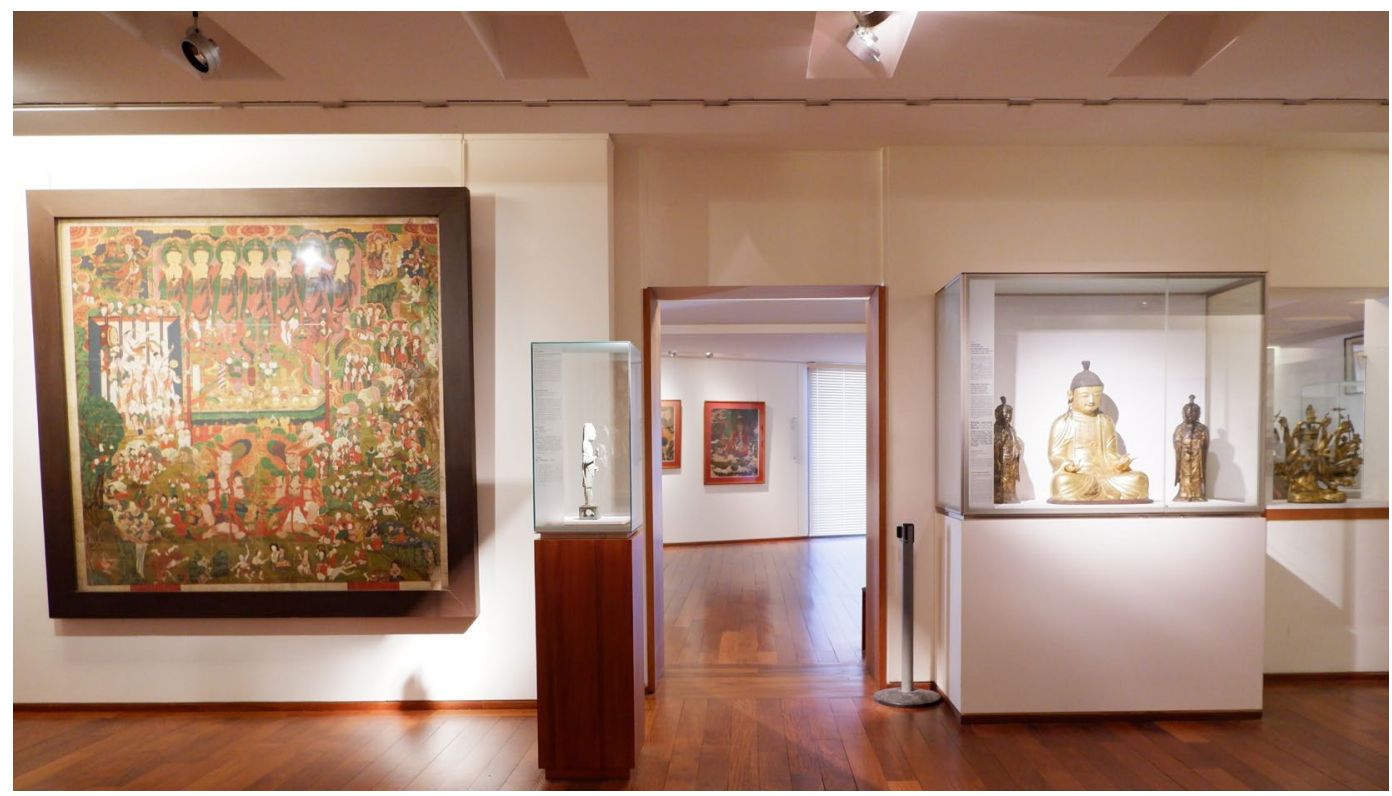

Figure 2. Display of archaeological and religious objects from the early Korean collection (photo by the author). 




Figure 3. The newly displayed Korean collection space (photo by the author).

culture to France for the long-term. The involvement of the South Korean agency subsequent to the early influences of two Frenchmen, and the subjectivities involved in both phases of development, thus contributed to the making of the gallery's "inbetween" state. The Korean gallery was produced neither wholly by Korean agency nor wholly by museum agency.

Another level of "inbetweenness" for the gallery is found in the discontinuity of the range of the museum's Korean collections; indeed, this is perhaps an opportunistic development of a re-representation of culture, as the present display illustrates. There has been a gap in the Korean collections between Korean agency (as cultural origin) and Western European agency (as early collectors and as the space of representation). In other words, the original Western selection of artifacts in the collections indicates a particular outsider and partial view of what should represent Korean culture. The newly displayed gallery (see Figure 3), however, includes Korean-selected additions that supplement the collections. Some of the newly displayed objects, for example, include an everyday painting and screens of the Joseon period (1392-1910) donated by contemporary painter Lee Ufan (b. 1936) (see Figure 4). While it represents an insider perspective, this is also a partial view of what should be in the gallery. Nonetheless, from two French collectors' collections of early folkloric material and high-quality objects to a Korean contemporary artist's addition of another genre, the history of the Korean collection and display at Musée Guimet refuses to be pinned down to a single, fixed cultural image.

The Korean gallery in Musée Guimet is a particular kind of Oriental/Asian arts and cultures display located in the heart of Paris. The Korean cultural materials' long journey from late nineteenth century Korea, to France, to becoming representative objects displayed in a contemporary Asian art museum, indicates temporal continuity, as well as change, in the representation on view. Examining the diverse agencies involved, such as the nineteenth century collectors on the 


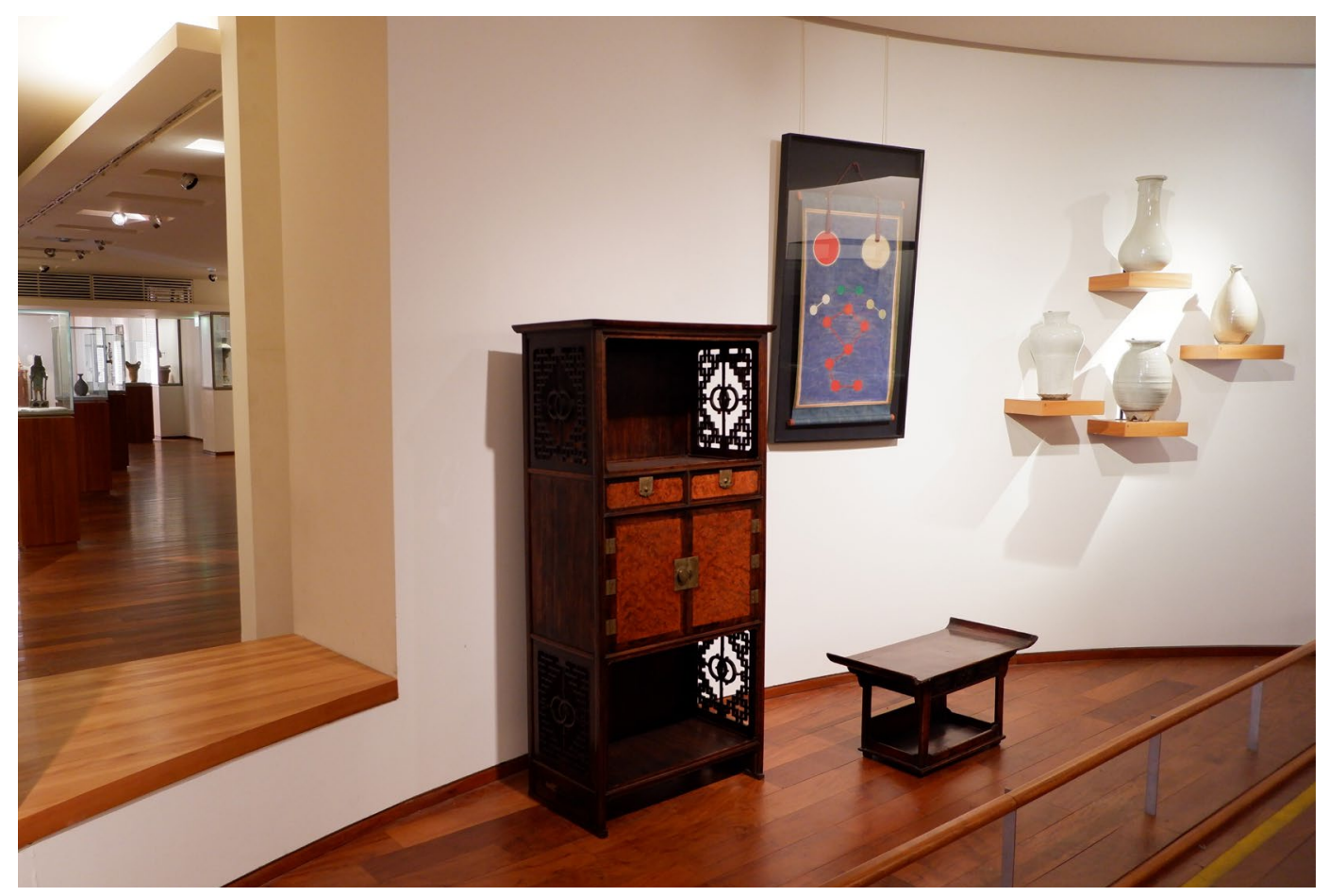

Figure 4. A threshold (on the left) between recently donated collection by Lee Ufan and the early collections (photo by the author).

one hand and Korean cultural organizations on the other, enhances our understanding of the present shape of the Korean exhibition. In this gallery space, we can see how the possibilities of ever-changing exhibition components and influences perpetuate the liminality and "inbetweenness" of collections (Dudley 2017).

Sumi Kim,

Hankuk University of Foreign Studies, Seoul

\section{REFERENCES}

Basu, Paul, ed. 2017. “The Inbetweenness of Things.” In The Inbetweenness of Things: Materializing Mediation and Movement Between Worlds, 1-20. London: Bloomsbury Publishing PLC.

Dudley, Sandra H. 2017. "The Buzz of Displacement: Liminality among Burmese Court Objects in Oxford, London and Yangon". In The Inbetweenness of Things: Materializing Mediation and Movement Between Worlds, ed. Paul Basu, 39-58. London: Bloomsbury Publishing PLC.

Dudley, Sandra H. 2021. Displaced Things in Museums and Beyond: Loss, Liminality and Hopeful Encounters. New York: Routledge.

The Korea Foundation. 2002. 10 Years History of the Korea Foundation 1992-2001. Seoul: The Korea Foundation.

Shin, Sangchel. 2013. "Korean Art Exhibition in the 19th Century's French Museum: Charles Varat's Journey to Korea and the Opening of Korean Gallery at the Guimet Museum." Korean Studies 45: 41-64. Korea University: Center for Korean Studies. 